\title{
Role of ethylene in responses of plants to nitrogen availability
}

\author{
M. I. R. Khan ${ }^{1}$, Alice Trivellini' ${ }^{2}$, Mehar Fatma ${ }^{1}$, Asim Masood ${ }^{1}$, Alessandra Francini², \\ Noushina Iqbal ${ }^{3}$, Antonio Ferrante ${ }^{4}$ and Nafees A. Khan ${ }^{1 *}$
}

${ }^{1}$ Department of Botany, Aligarh Muslim University, Aligarh, India, ${ }^{2}$ Institute of Life Sciences, Scuola Superiore Sant'Anna, Pisa, Italy, ${ }^{3}$ Department of Botany, Jamia Hamdard University, New Delhi, India, ${ }^{4}$ Department of Agricultural and Environmental Sciences, Università degli Studi di Milano, Milan, Italy

\section{OPEN ACCESS}

Edited by:

Rafael Pérez-Vicente, University of Córdoba, Spain

Reviewed by:

Bahar Yildiz Kutman,

University of California, Davis, USA Wen-Hao Zhang, Institute of Botany, Chinese Academy of Sciences, China

*Correspondence: Nafees A. Khan naf9@lycos.com

Specialty section: This article was submitted to Plant Nutrition, a section of the journal Frontiers in Plant Science

Received: 16 July 2015 Accepted: 14 October 2015 Published: 30 October 2015

Citation: Khan MIR, Trivellini A, Fatma M, Masood A, Francini A, lqbal N, Ferrante A and Khan NA (2015) Role of ethylene in responses of plants to nitrogen availability.

Front. Plant Sci. 6:927. doi: 10.3389/fpls.2015.00927
Ethylene is a plant hormone involved in several physiological processes and regulates the plant development during the whole life. Stressful conditions usually activate ethylene biosynthesis and signaling in plants. The availability of nutrients, shortage or excess, influences plant metabolism and ethylene plays an important role in plant adaptation under suboptimal conditions. Among the plant nutrients, the nitrogen $(\mathrm{N})$ is one the most important mineral element required for plant growth and development. The availability of $\mathrm{N}$ significantly influences plant metabolism, including ethylene biology. The interaction between ethylene and $\mathrm{N}$ affects several physiological processes such as leaf gas exchanges, roots architecture, leaf, fruits, and flowers development. Low plant $\mathrm{N}$ use efficiency (NUE) leads to $\mathrm{N}$ loss and $\mathrm{N}$ deprivation, which affect ethylene biosynthesis and tissues sensitivity, inducing cell damage and ultimately lysis. Plants may respond differently to $\mathrm{N}$ availability balancing ethylene production through its signaling network. This review discusses the recent advances in the interaction between $\mathrm{N}$ availability and ethylene at whole plant and different organ levels, and explores how $\mathrm{N}$ availability induces ethylene biology and plant responses. Exogenously applied ethylene seems to cope the stress conditions and improves plant physiological performance. This can be explained considering the expression of ethylene biosynthesis and signaling genes under different $\mathrm{N}$ availability. A greater understanding of the regulation of $\mathrm{N}$ by means of ethylene modulation may help to increase NUE and directly influence crop productivity under conditions of limited $\mathrm{N}$ availability, leading to positive effects on the environment. Moreover, efforts should be focused on the effect of $\mathrm{N}$ deficiency or excess in fruit trees, where ethylene can have detrimental effects especially during postharvest.

Keywords: ethylene, mineral nutrients, nitrogen availability, $\mathrm{N}$ use efficiency, phytohormones

\section{INTRODUCTION}

The classical plant hormone, ethylene has emerged as a potent molecule to regulate numerous physiological and morphological responses in plants by interacting with other signaling molecules (Iqbal et al., 2012; Khan and Khan, 2014; Fiebig and Dodd, 2015; Khan et al., 2015). Ethylene plays an important regulatory roles in plant responses to mineral nutrients availability, such as nitrogen (N; Iqbal et al., 2015), phosphorous (P; Li et al., 2009), potassium (K; Jung et al., 2009), calcium (Ca; Xu et al., 2010), magnesium (Mg), manganese (Mn; Dorling et al., 2011), copper (Cu; Arteca and Arteca, 2007), zinc (Zn; Khan and Khan, 2014) and controls plant responses under both optimal 
and stressful conditions (Iqbal et al., 2013). The ethylene biosynthesis and plant responses vary with the availability of mineral nutrients (Iqbal et al., 2013).

Nitrogen is an important nutrient required for plant growth and development as it is a core constituent of a plant's nucleic acid, proteins, enzymes, and cell wall and pigment system (Krapp, 2015). Plants are frequently exposed to $\mathrm{N}$ stressed conditions, excess $\mathrm{N}$ due to application of $\mathrm{N}$ fertilizers or deficiency. While low $\mathrm{N}$ limits the growth of crop plants (Iqbal et al., 2015), the loss of excess $\mathrm{N}$ fertilizers contributes to environmental pollution (Gastal and Lemaire, 2002). The availability of $\mathrm{N}$ is of agricultural concern because plant metabolism is differently affected by excess, optimal and deficient levels (Iqbal et al., 2015). In maintaining the physiological status of plants under these conditions, the role of ethylene in responding to $\mathrm{N}$ status in plants has been identified (Tian et al., 2009; Fiebig and Dodd, 2015; Iqbal et al., 2015). The availability of $\mathrm{N}$ concentrations modify the effect of ethylene and plant responses, like other mineral nutrients such as phosphate (Li et al., 2009), sulfate (Zuchi et al., 2009), potassium (Shin and Schachtman, 2004), iron (Romera and Alcantara, 1994). Fiebig and Dodd (2015) have recently reported that $\mathrm{N}$ supplementation of $10 \mathrm{mM}$ returned ethylene concentrations in over-irrigated Solanum lycopersicum plants to the levels of well-drained plants, leading to an increase in shoot fresh weight that correlated with decreased ethylene levels. This can be explained considering that over-irrigation induces nitrate leakage and subsequently N deficiency. Similarly, N differentially regulates proline and ethylene biosynthesis in order to alleviate salt-induced photosynthetic inhibition in mustard plants (Iqbal et al., 2015). It has been also shown that exogenous ethylene (applied as ethephon, an ethylene releasing compound) increases $\mathrm{N}$ assimilation and photosynthesis in Brassica juncea plants subjected to different levels of $\mathrm{N}$ (Khan et al., 2008; Iqbal et al., 2011). In B. juncea, Iqbal et al. (2015) have shown that plants exhibited lesser photosynthesis and growth when treated with $5 \mathrm{mM} \mathrm{N}$ than $10 \mathrm{mM} \mathrm{N}$, whereas $20 \mathrm{mM} \mathrm{N}$ was inhibitory under no-stress condition. This indicated that these levels were low, sufficient and excess, respectively. The inhibitory effect of excess- $\mathrm{N}$ was related to high ethylene production, but under salt stress, as the demand for $\mathrm{N}$ increased the excess-S optimized ethylene and led to higher proline production and promoted photosynthesis and growth (Iqbal et al., 2015). Similarly, it has been found that a high $(10 \mathrm{mM})$ concentration of $\mathrm{N}$ inhibits the lateral root growth of Arabidopsis thaliana, although the number and length of lateral roots of the etr1-3 and ein2-1 mutants were less affected than wild-type plants. The leaf longevity in Agropyron cristatum was affected by ethylene at different $\mathrm{N}$ levels (Ren et al., 2013). Plants under low $\mathrm{N}$ conditions accelerate the development and usually show early transition to reproductive stage, reaching earlier to senescence stage. Plants grown to high $\mathrm{N}$ availability have longer vegetative stage and delayed senescence. In both cases, ethylene has a pivotal role, since it is also known as senescence hormone.

This review explored the state of the art of the information available on the role of $\mathrm{N}$ in modulating ethylene responses in whole plant and different plant organs. The information related to ethylene and $\mathrm{N}$ availability has been critically discussed arising due to the contrary results obtained in different works. Moreover, the lack of information has been highlighted indicating where further investigations should be addressed.

\section{N AVAILABILITY AND ETHYLENE BIOSYNTHESIS AND SIGNALING}

The literature has only recently started to explore the nature of the relationships between plant hormones and macronutrient signaling. The following pages describe recent advances in the study of the ethylene signaling pathway in the presence of $\mathrm{N}$ perturbation and provide new information based on in silico analyses.

The availability of $\mathrm{N}$ is one of the main factors limiting plant growth and development. Ammonium $\left(\mathrm{NH}_{4}{ }^{+}\right)$and nitrate $\left(\mathrm{NO}_{3}{ }^{-}\right)$are the predominated inorganic forms of nitrogen taken up from the soil. In particularly, nitrates are the most readily available form of $\mathrm{N}$ for root absorption because it is not absorbed by colloids. Nitrate is assimilated by higher plants after being reduced to nitrite and then ammonium as a result of the sequential action of nitrate and nitrite reductases, and the $\mathrm{NH}_{4}{ }^{+}$can be subsequently assimilated into glutamate and glutamine via the glutamine synthase (GS)/glutamate oxyglutarate aminotransferase cycle (GOGAT) (Crawford, 1995). These metabolic intermediates act as important signaling molecules or as the major amino donors for the synthesis of other amino acids and $\mathrm{N}$-containing compounds, thus sustaining plant growth and development, and plant responses to biotic and abiotic stresses (Stitt, 1999; Forde and Lea, 2007; Vidal and Gutiérrez, 2008; Mur et al., 2012; Renault et al., 2013). The assimilation of $\mathrm{N}$ by plants, or its incorporation in plants, depends on the availability of light and activities of photosynthesis because $\mathrm{N}$ can only be incorporated if there are enough carbon (C) skeletons.

It is thought that $\mathrm{N}$ acts as a signaling element in plants, but very little is known about how this occurs (Lea and Miflin, 2003) or how $\mathrm{N}$ interacts with the ethylene biosynthesis and signaling pathway that is closely associated with complex environmental stresses. Ethylene is essential for regulating plant responses to biotic and abiotic stresses, and plays a key role in regulating growth and senescence (Lin et al., 2009). Ethylene production rapidly increases in plants subjected to wounding, flooding, drought, osmotic shock, senescence, ozone, and pathogen/insect invasion (Wang et al., 2002; van Loon et al., 2006; Di Baccio et al., 2012), and this leads to the activation of cell responses through the ethylene signaling pathway and its interactions with the signaling pathways of other plant hormones (Overmyer et al., 2000; Wang et al., 2002; Trivellini et al., 2014). Ethylene is synthesized by two enzymes encoded by small gene families: 1 aminocyclopropane 1 carboxylic acid (ACC) synthase (ACS) and ACC oxidase (ACO). The reaction is first catalyzed by ACS, which converts $S$-adenosyl-L-methionine (SAM) to ACC, and then ACC oxidase catalyzes the conversion of ACC to ethylene with the release of $\mathrm{CO}_{2}$ and cyanide (Wang et al., 2002). ACS is the rate-limiting step in ethylene biosynthesis, and controls the main step in stress-induced ethylene regulation (Tsuchisaka 
et al., 2009), whereas ACO activity is constitutively present in most vegetative tissues. The ethylene biosynthetic pathway is relatively simple, but its production is strictly regulated at various levels. In addition to transcriptional regulation (Tsuchisaka and Theologis, 2004a,b), post-translational regulation is pivotal for developmental and stress-induced ethylene production (Christians et al., 2009; Han et al., 2010; Skottke et al., 2011; Lyzenga et al., 2012).

In order to investigate the role of ethylene depending on $\mathrm{N}$ availability, we first listed the genes involved in ethylene biosynthesis, signaling and responses by searching The Arabidopsis Information Resource (TAIR ${ }^{1}$ ) (Supplementary Table S1) and then analyzed the publicly available microarray data on the Affymetrix ATH1 microarray platform (as of June 2015) using Genevestigator (Hruz et al., 2008). A similarity search subsequently enabled the determination of lists of the same genes regulated upon a given $\mathrm{N}$ perturbation (Supplementary Table S1). The analysis considered the expression profiles of the genes that showed a $>2$-fold change in transcription level $(P<0.01)$ under conditions of nitrate starvation and low or high $\mathrm{N}$ content, and the fold-change values were hierarchically clustered by genes and experiments using Euclidean distances.

This meta-profiling showed that the ethylene biosynthetic pathway is regulated by $\mathrm{N}$ conditions (Figure 1A), and that the genes involved in ethylene biosynthesis appeared to be transcriptionally active under these conditions. In the case of nitrate starvation, ACC synthase ACS7 and a putative ACO (and ACS10) were strongly repressed in seedlings, but both were induced in rosette samples treated with low and high $\mathrm{N}$ levels, whereas ACC synthases ACS8 and ACS4, and ACC oxidase $A C O 1, A C O 5$ and $A C O 2$ were negatively regulated under both conditions. However, ETO1 (OVERPRODUCER1), SAM1, EOL1like (ETO-like) and other putative $A C O$ were induced in response to $\mathrm{N}$ deprivation and low/high $\mathrm{N}$ conditions. It is tempting to hypothesize that the multi-gene ACS and ACO families are both temporally and spatially differentially expressed under low $\mathrm{N}$ environmental conditions, as has previously been shown in the case of stresses such as Pi-deprivation (Kim et al., 2008; Roldan et al., 2013), and depend on the species, tissue and developmental stage of the plants (Inaba et al., 2007; Trivellini et al., 2011). A large-scale transcriptome analysis has detected an ACO6 homolog involved in ethylene synthesis during the early response of cucumber seedlings to $\mathrm{N}$ deficiency (Zhao et al., 2015), and the induction of an ACO4 homolog and ACOlike transcript has been observed in response to $\mathrm{N}$ starvation in studies of chronic low N conditions (Bi et al., 2007; Peng et al., 2007).

It is also worth noting that suboptimal nutrient supply promotes leaf senescence (Mei and Thimann, 1984; Jibran et al., 2013). Balazadeh et al. (2014) have recently reported that plants undergoing senescence retain the capacity to sense and respond to the availability of $\mathrm{N}$ nutrition by reversing the senescence phenotype induced by $\mathrm{N}$ starvation. In this study, the expression of ACS2, ACS6, and ACS7, and ACO2, ACO3, and ACO4 was increased during senescence, but only ACS6 was first induced

${ }^{1}$ https://www.arabidopsis.org/ after 4 days of $\mathrm{N}$ deficiency and then reduced $3 \mathrm{~h}$ after $\mathrm{N}$ resupply. ACO2 and ACO4 transcript levels were also increased by $\mathrm{N}$ deprivation and then significantly down-regulated after 3 days of $\mathrm{N}$ resupply, once again highlighting the complexity of ACS and ACO regulation by various stresses signals.

Ethylene production (particularly the rapid breakdown of ACS proteins) is also tightly controlled by means of protein degradation (Christians et al., 2009). The recently characterized Arabidopsis mutant hps3 (Wang et al., 2012), which is hypersensitive to $\mathrm{Pi}$ starvation, was previously identified as an allele of the ETO1 gene that negatively regulates ethylene biosynthesis by producing 10-50 times more ethylene than the wild type (Wang et al., 2004), and our Genevestigator analysis showed that ETO1 and EOL1 are weakly expressed under low $\mathrm{N}$ conditions. Although these findings potentially define the role of ethylene in regulating multiple plant responses to conditions including $\mathrm{N}$ starvation, there is a need for further experimental analyses aimed at identifying the molecular components that interact with ethylene signaling in regulating plant responses to $\mathrm{N}$.

A meta-analyses of the ethylene receptors and mitogenactivated protein kinases (MAPK, MPK, or MKK) linking upstream sensors to the downstream processes of hormonal responses under conditions of $\mathrm{N}$ deprivation shows that ERS2 and EIL1 are down-regulated, whereas the MPKs involved in ethylene signaling are all induced (Figure 1B). Previous studies have shown that MPK3 can be activated by various MKKs that participate in specific signaling pathways: for example the MKK4/MKK5/MKK9 pathway activates MPK3/MPK6 to promote ethylene production (Liu et al., 2008), and MKK9 activates MPK3/MPK6 to regulate leaf senescence (Zhou et al., 2009) and ethylene signaling (Yoo et al., 2008). However, it is not yet known whether MAPK signaling cascades are directly involved in regulating plant responses to various $\mathrm{N}$ conditions.

Nitrogen deficiency may play a positive role in ethylene biosynthesis and signaling as in silico analysis reveals the slight down-regulation of CTR1 and up-regulation of EIN3 under conditions of $\mathrm{N}$ starvation and low/high $\mathrm{N}$ levels. Zheng et al. (2013) have similarly found that low-level nitrate treatment induces rapid bursts of ethylene production and regulates the expression of the ethylene signaling components CTR1, EIN3 and EIL1, and NRT2.1 in wild-type plants. The authors used $\mathrm{NO}_{3}{ }^{-}$transporter mutants $n r t 1.1$ and $n r t 2.1$ and the ethylene mutants ctr1-1 and ein3-1eil1-1, and elegantly proposed that $\mathrm{NO}_{3}{ }^{-}$deficiency induces a negative feedback loop between the transcription of NRT2.1 and ethylene biosynthesis and signaling that allows plants to fine tune nitrate acquisition during the exploration of dynamic soil conditions.

The gene sets specified in Figure 1C were further classified into gene ontology (GO) categories in order to help the identification of over-representation. Sixty-nine genes were initially uploaded to the DAVID Bioinformatics Resources 6.7 platform (Huang et al., 2009²) in order to identify significantly enriched biological themes by examining enrichment in more than 40 publicly available annotation categories (Trivellini et al.,

${ }^{2}$ http://david.abcc.ncifcrf.gov/ 


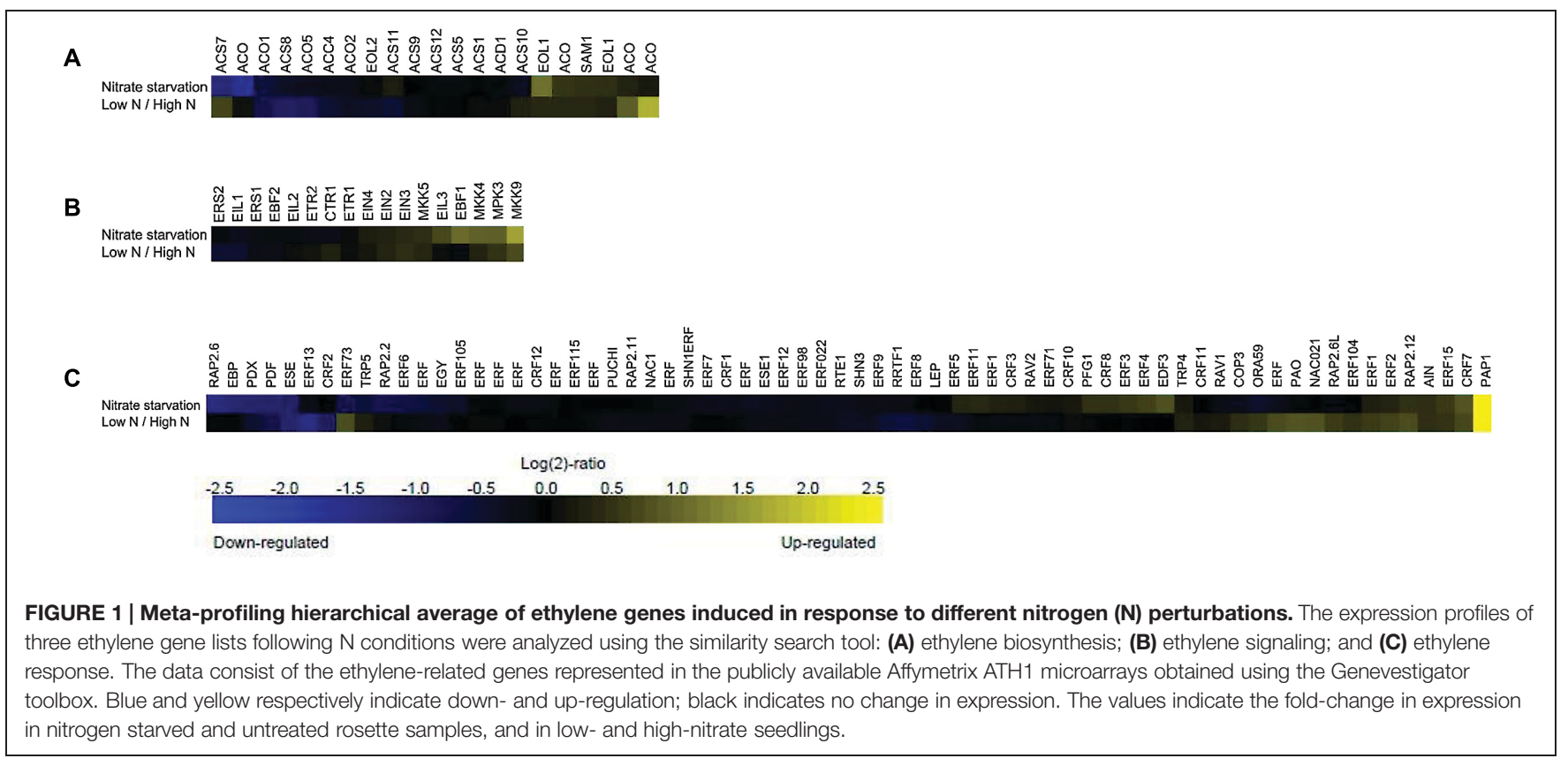

2012). The analysis identified six clusters that showed significant enrichment, with enrichment scores (ES) ranging from 69.951.37 (Table 1). The most enriched annotation cluster (ES 69.95) was not surprisingly associated with the genes belong to the Apetala2/ethylene response factor (AP2/ERF-TF) super family; the second cluster contained genes with transcription repressor activity (ES 8.68); the third consisted of genes related the biological processes of root and lateral root development (ES 3.45); the fourth included genes involved in the negative regulation of the ethylene-mediated signaling pathway (ES 2.33); the fifth included genes involved in the response to cytokinin (CK) stimuli (ES 1.49); and the sixth the genes involved in the response to jasmonic acid stimuli (ES 1.39).

The AP2/ERF-TF family is involved in signaling processes and the responses to environmental stresses (Vogel et al., 2012). Most importantly, there is increasing evidence that AP2/ERF proteins are components of multiple signaling pathways as they control the expression of downstream genes and tune cross-talk between the signaling pathways involving macronutrients deficiency (Kim et al., 2012; Cai et al., 2013; Takehisa et al., 2013). Genome-scale transcriptional profiling of cucumber seedlings has shown that seven ERF genes are regulated under conditions of $\mathrm{N}$ starvation (Zhao et al., 2015), and comprehensive expression profiling of $\mathrm{N}$ starvation-responsive miRNAs has identified miR829.2, which is predicted to target an AP2 domain ethylene response factor required for morphogenesis in the early lateral root primordium of Arabidopsis (Liang et al., 2012), thus highlighting the important role of this transcription family in N-starved root development.

Furthermore, as was done in the case of the genes involved in the ethylene biosynthesis and perception machinery, the ethylene response gene list was compared with the publicly available microarray data using the Perturbations tool in the Condition Search toolset of Genevestigator (Hruz et al., 2008).
All of the ethylene response genes seemed to be transcriptionally active under condition of $\mathrm{N}$ starvation and/or low/high $\mathrm{N}$ levels, with the PURPLE ACID PHOSPHATASE 1 (PAP1), PYRIDOXINE BIOSYNTHESIS 1.1 (PDX1.1), PLANT DEFENSIN $1.2 B$ (PDF1.2B) and ETHYLENE AND SALT INDUCIBLE 3 (ESE3) responding strongly to both types of $\mathrm{N}$ perturbation (Figure 1C). PAP1 encodes transcription factors regulating the expression of anthocyanin biosynthetic genes in vegetative tissues. PAP1 expression is a frequent plant response to stress conditions such as drought, heat, chilling, $\mathrm{N}$ deficiency and in response to abscisic acid (ABA), and the sugars in which anthocyanin is accumulated (Luo et al., 2012). The availability of $\mathrm{N}$ represses anthocyanin biosynthesis-related gene expression (Rubin et al., 2009) whereas N deficiency stimulates it (Peng et al., 2008). As it is known that ethylene stimulates the expression of the genes related to anthocyanin biosynthesis (Afifi et al., 2003; El-Kereamy et al., 2003), N starvation could induce a transient rise in ethylene production and signaling (Zheng et al., 2013). A new allele of ROOT HAIR DEFECTIVE3 (RHD3) with an anthocyanin over-accumulation phenotype under conditions of $\mathrm{N}$ starvation has recently been identified (Wang et al., 2015), and the authors speculate that RHD3 achieves its negative effect on anthocyanin biosynthesis via an ethylene-regulating pathway involving the ETR1, EIN2, and EIN3/EIL1-mediated signaling cascade. Further investigations are needed to clarify the molecular mechanism of RDH3 underlying ethylene signal transduction.

Interestingly, RAP 2.6, RAP $2.3(E B P)$, and RAP 2.2 were significantly down-regulated in the $\mathrm{N}$ starvation experiment, whereas $R A P 2.12$ and $R A P 2.6 L$ were weakly up-regulated under both conditions, and ERF73 seemed to be differentially regulated (Figure 1C). These genes of the AP2/ERF family are responsible for modulating tolerance to the hypoxic stresses encountered by plants: AtRAP2.2 and RAP2.3 are important for 
TABLE 1 | Functional annotation clustering using DAVID bioinformatics resources 6.7.

\begin{tabular}{|c|c|c|c|c|}
\hline Cluster number & Enrichment score & Category & Term & Gene count \\
\hline 1 & 69.95 & GOTERM_BP_FAT & Response to ethylene stimulus & 61 \\
\hline 2 & 8.68 & GOTERM_MF_FAT & Transcription repressor activity & 9 \\
\hline 3 & 3.45 & GOTERM_BP_FAT & Root and lateral development & 6 \\
\hline 4 & 2.33 & GOTERM_BP_FAT & Negative regulation of ethylene mediated signaling pathway & 3 \\
\hline 5 & 1.49 & GOTERM_BP_FAT & Response to cytokinin stimulus & 4 \\
\hline 6 & 1.39 & GOTERM_BP_FAT & Response to jasmonic acid stimulus & 6 \\
\hline
\end{tabular}

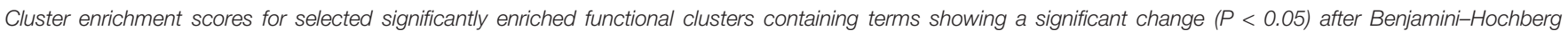

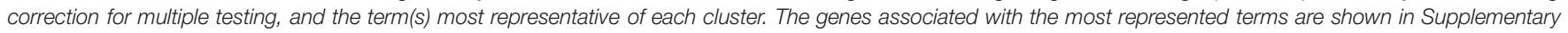
Table S2.

ethylene-mediated tolerance to hypoxia in Arabidopsis seedlings (Hinz et al., 2010; Limami et al., 2014), and the same is true of ERF73, the hypoxia-responsive ERF1 gene (HRE1) (Licausi et al., 2010); the overexpression of RAP2.6L delays the waterlogging induced by premature senescence and may function through the ABI1-mediated ABA signaling pathway (Liu et al., 2012); $R A P 2.12$ is involved in the activation of hypoxic gene expression and ethylene responses (Licausi et al., 2011; Zhao et al., 2012); and $R A P 2.6$ is involved in the response to ABA, wounding, jasmonic acid, salt, cold, and osmotic stresses (Fowler and Thomashow, 2002; Zhu et al., 2010). A number of studies have shown that hypoxic stress can be mitigated by nitrate fertilization (Morard et al., 2004; Horchani et al., 2010), but also that nitrate uptake and assimilation can be affected by oxygen-limiting conditions (Oliveira and Sodek, 2013; Oliveira et al., 2013). It therefore seems to be clear that there is a link between $\mathrm{N}$-limiting conditions and the regulation of the genes associated with hypoxia. The ethyleneresponsive genes typically involved in hypoxia are potential connectors in the gene/metabolite/hormone-related network of response to $\mathrm{N}$ starvation, but further studies are necessary in order to verify their possible role in the $\mathrm{N}$ assimilation and signaling pathway.

\section{ETHYLENE RESPONSES TO VARYING LEVELS OF N AVAILABILITY}

The N status of a plant influences its metabolism and growth, and can affect the synthesis of the building block metabolites and the distribution of growth substances. This interdependence is due to the fact that nutrient deficiency or excess affect the concentrations of specific hormones capable of directing the translocation and accumulation of nutrients (Kuiper, 1988; Kuiper et al., 1989), and a similar relationship has also been reported in the case of nutrient and ethylene interactions. Ren et al. (2013) have recently found that the addition of $\mathrm{N}$ reduces leaf longevity mainly by altering leaf ethylene production: this result was substantiated by the fact that the cobalt chloride-induced inhibition of ethylene biosynthesis reduced leaf $\mathrm{N}$ concentration and leaf longevity, presumably because a high $\mathrm{N}$ concentration stimulates the activities of the enzymes associated with ethylene synthesis (Tian et al., 2009). Increased ethylene production may also be involved in modulating nitrate transporters (Tian et al., 2009) and nitrate metabolism (Leblanc et al., 2008) at high nitrate levels. A nitrate concentration of $10 \mathrm{mM}$ increases the expression of genes encoding ACS and ACO (AtACS and AtACO), and leads to a sudden increase in ethylene production in $A$. thaliana plants. Furthermore, the upregulation and downregulation of nitrate transporters (AtNRT1.1 and AtNRT2.1) was observed by exogenously applying the ethylene synthesis precursor ACC and AVG in low and high nitrate concentration, respectively, whereas the etr1-3 and ein2-1 mutants were insensitive to high nitrate concentrations (Tian et al., 2009). A very interesting study by Misyura et al. (2014) found that ethylene may act as a plant-plant communication signal in rice under conditions of high-density stress, when the expression of ethylene-associated genes was related to ethylene homeostasis. The authors showed that $\mathrm{N}$ availability can influence the growth of rice plants dependent on ethylene homeostasis, and that the developmental characteristics of plants were negatively affected under high density conditions when $\mathrm{N}$ was limited $\left(3 \mathrm{mM} \mathrm{NO}_{3}{ }^{-}\right)$or sufficient $\left(10 \mathrm{mM} \mathrm{NO}_{3}{ }^{-}\right)$. The availability of $\mathrm{N}$ influences the evolution of ethylene and affects photosynthesis, stomatal conductance and growth in B. juncea plants (Khan et al., 2008; Iqbal et al., 2011). Field experiments demonstrated that the application of ethephon (ethylene-releasing compound) to plants grown with $\mathrm{N}$ levels of 40 and $80 \mathrm{mg} \mathrm{N} \mathrm{kg}^{-1}$ increased ethylene production and photosynthesis (Iqbal et al., 2011). It has also been suggested that the application of ethephon induces stomatal and carboxylation efficiency and the Calvin cycle enzymes in mustard plants grown at various $\mathrm{N}$ levels, with significant interaction between ethylene, $\mathrm{N}$ availability, and photosynthetic characteristics.

Improving the acquisition of macronutrients such as $\mathrm{N}$, phosphorus $(\mathrm{P})$ and potassium $(\mathrm{K})$ in poorly fertile soils is one of the main objectives of program aimed at reducing the use of fertilizers and increasing the efficiency of nutrient use (Hirel et al., 2007; Lynch, 2007). The efficient use of $\mathrm{N}$ fertilizer is essential to ensure a better return on investment and minimize the adverse effects of accumulated reactive $\mathrm{N}$ species on the environment. It is therefore important to increase the $\mathrm{N}$ use efficiency (NUE) of plants in order to avoid $\mathrm{N}$ wastage and accumulation. NUE, the efficiency of carboxylation and water use, and the dry mass of mustard plants increased at different levels of $\mathrm{N}$ in combination with ethephon (Iqbal et al., 2011). Exogenously sourced ethylene enhances photosynthetic NUE and promotes photosynthesis in various types of mustard plant with differing photosynthesising capacity (Iqbal et al., 2012). The application of 
ethrel at basal $80 \mathrm{~kg} \mathrm{~N} \mathrm{ha}^{-1}$ increased the efficiency of $\mathrm{N}$ uptake and use in mustard plants, and that the exogenous application of ethephon increased stomatal conductance, photosynthesis and growth under conditions of $\mathrm{N}$ deficiency and optimization as a result of increased NUE (Mir, 2002). It has also been found that, under $\mathrm{N}$-deficient conditions, greater endogenous ethylene evolution decreases NUE, photosynthesis and growth in mustard plants (Iqbal et al., 2011). However, high levels of ethylene can also have a negative impact on plant growth and photosynthesis. Under certain conditions the increase of the ethylene sensitivity and ethylene action overcomes $\mathrm{N}$ deficiency by increasing photosynthesis and growth in plants with sufficient or deficient $\mathrm{N}$ availability (Iqbal et al., 2011). Recently has been reported that $\mathrm{N}$ availability regulates ethylene formation, which regulates plant $\mathrm{N}$ content and nitrate reductase (NR) activity (Iqbal et al., 2015). Subsequently ethylene increases the proline content and salt tolerance of $B$. juncea plants, and improves photosynthesis and growth.

Nitrogen deficiency leads to strong synergistic interactions between volicitin and ethylene, indicated by the induction of volatile sesquiterpene and indole emissions. Whereas volicitininduced volatiles are greatly reduced in plants with medium $\mathrm{N}$ levels, and there are virtually no interactions with ethylene. The altered volicitin-ethylene interaction due to changes in the magnitude of induced volatile emissions observed in plants with low and medium levels of $\mathrm{N}$ availability is consistent with the known increase in ethylene sensitivity that occurs during $\mathrm{N}$ deficiency (Schmelz et al., 2003). $\mathrm{N}$ deprivation enhances the sensitivity of ethylene-responsive cells in root cortex, thus leading to cell lysis and aerenchyma formation, and that the exogenous application of ethylene $\left(1.0 \mu \mathrm{L} \mathrm{L}^{-1}\right)$ further promoted aerenchyma formation in N-starved roots (He et al., 1992). N starvation increases the number or affinity of root receptors, thus allowing roots to responds to lower concentrations of ethylene than those found in unstressed roots. Plants supplied with high nitrate levels $(30 \mathrm{mM})$ increased their aerial ACC content by translocating it from the roots to the shoot in order to induce ethylene synthesis in the leaves by means of ACC oxidase (Saiz-Fernández et al., 2015). Ethylene plays a role in the regulation of fully developed and expanding leaves by reducing leaf area when ethylene accumulates in developing tissues (Young et al., 2004; He et al., 2009). The interaction between ethylene and $\mathrm{N}$ may also increase the synthesis of amino acids, proteins and enzymes. The production of ethylene by soluble solids could be due to increased synthesis of the amino acid cysteine, a precursor of ethylene that may be extended to synthesize other amino acids (Kaack and Pedersen, 2014). Zhao et al. (2015) studied changes in the expression of transcriptional factor and kinase genes at transcriptional level during the early stage of the $\mathrm{N}$ deficiency response, and observed seven ERF and three MYB transcription factors, five NAC domaincontaining proteins, and four zinc finger proteins. Bi et al. (2007) and Peng et al. (2007) have found that ACO4 and another ACO homologue showed responses to $\mathrm{N}$ deficiency: ethylene production generally increases upon $\mathrm{N}$ deprivation but, in comparison with explants in standard MS medium, ethylene production by rhizome explants in low $\mathrm{N}$ medium was reduced after 1-3 months of culture. Zhang et al. (2013) found low nitrate treatment-induced rapid bursts of ethylene production and the regulated expression of the ethylene signaling components CTR1,EIN3 and EIL1 in wild-type A. thaliana (Col-0) seedlings, and enhanced ethylene response reporter EBS:GUS activity in Col-0 and the ethylene mutants ein3-1, eil11 and $\operatorname{ctr1-1.}$ The treatment also caused the up-regulation of NRT2.1 expression, which was responsible for enhanced highaffinity nitrate uptake, and had a positive effect on ethylene biosynthesis and signaling. However, ethylene down-regulated NRT2.1 expression and reduced high-affinity nitrate uptake, thus suggesting that nitrate deficiency gives rise to a negative feedback loop between NRT2.1 expression and ethylene biosynthesis and signaling, which may contribute to the fine tuning of plant nitrate acquisition during the dynamic exploration of soil conditions.

\section{ETHYLENE PRODUCTION IN DIFFERENT PLANT ORGANS AT DIFFERENT LEVELS OF N AVAILABILITY}

Ethylene can be produced in any plant tissue and is modulated by various internal and external factors. The responses of different organs to ethylene vary, depending on tissue sensitivity and the stage of plant development.

\section{ROOT RESPONSES}

The efficient absorption of macronutrients such as $\mathrm{N}$, and developing the traits involved in remodeling root system architecture in order to acquire $\mathrm{N}$ more efficiently, are important targets of modern plant breeding program (Forde, 2014). Phytohormones are involved in controlling root development and architecture by means of $\mathrm{N}$-mediated signals, and recent transcriptomic studies have shown that auxin, ethylene and CK are involved in root architectural responses to nitrates (Tian et al., 2009; Ruffel et al., 2011; Jin et al., 2012). Lemaire et al. (2013) found that ethylene signaling affects nitrate uptake and the expression of $B n N R T$ nitrate transporter genes depending on changes in the length of exploratory and root hair systems. Different species, and even the same species under different growing conditions, may have opposite behaviors. In comparison with the wild type, Never Ripe (NR) ethylene-insensitive tomato mutants have more below-ground roots and fewer above-ground adventitious roots. Interactions and cross-talk with other plant hormones can lead to different responses. The application of exogenous auxin leads to different behavior (Clark et al., 1999), thus indicating that the effects of ethylene depend on its interaction with auxins as well as abiotic stresses such as nutrient deficiency.

Ethylene deficiency generally induces root development in order to increase the root biomass necessary for exploring a wide area of soil in search of the deficient nutrient. Ethylene can modulate root waving, and the direction and length of root growth (Buer et al., 2003), but the response can be affected 
by interactions with nutrients. More studies should be carried out in order to investigate root architecture under conditions of $\mathrm{N}$ deficiency or excess using ethylene inhibitors. It has been found that $\mathrm{N}$ starvation simultaneously increases ethylene evolution and induced aerenchyma formation in the roots of Zea mays plants (Drew et al., 2000). Basal roots are more sensitive to ethylene than apical roots (Takahashi et al., 2015). The induction of aerenchyma is also a means of adapting to flooding, and oxygen shortage can initiate programmed cell death (PCD) in roots. Hypoxia associated with $\mathrm{N}$ deficiency enhances aerenchyma development, whereas anoxia inhibits or reduces it because the complete lack of oxygen blocks the ACC oxidase enzyme, which catalyzes the last step in ethylene biosynthesis. The use of ethylene biosynthesis and action inhibitors has shown that ethylene is directly involved in PCD in roots (He et al., 1992). High N (especially nitrate) availability in soils induces ethylene biosynthesis in roots. A number of studies have investigated the effects of ethylene and high nitrate content on legumes, in which ethylene biosynthesis inhibits the nodules necessary for $\mathrm{N}$ fixation and lateral root development (Caba et al., 1998; Okushima et al., 2011). The effect of the interaction of ethylene and high nitrate concentration on nodule formation has been elegantly demonstrated in various experiments using ethylene activators and biosynthesis inhibitors such as AVG and silver (Peters and Crist-Estes, 1989; Caba et al., 1998; Nukui et al., 2000). The inhibition of nodule formation is negative because it reduces $\mathrm{N}$ fixation in leguminous plants; however, from an ecological point of view, plants do not need to develop nodules for gaseous $\mathrm{N}$ fixation in soils that are rich in $\mathrm{N}$, particularly nitrates.

Ethylene causes a triple response in Arabidopsis roots: the rapid down-regulation of cell elongation, the induction of ectopic root hairs, and an increase in root width. Le et al. (2001) found that slight changes in the concentration of environmental ethylene in Arabidopsis modulate the elongation of target cells in root epidermis, and suggested that ethylene is a means of fine and fast tuning root elongation in nature. It has also been demonstrated that $\mathrm{C} / \mathrm{N}$ balance is involved in root morphogenesis (Malamy and Ryan, 2001; Martin et al., 2002), and that $\mathrm{C}$ and $\mathrm{N}$ interact with the major plant hormones (Sheen et al., 1999). Le et al. (2001) reported that ethylene inhibits the elongation of root cells, but does not affect root length in the root regions in which cell wall formation occurs before an increase in ethylene level. Increased ethylene synthesis with low concentrations of ACC promotes the initiation of lateral root primordial; however, treatment with higher ACC doses inhibits the formation of new primordia, but promotes the emergence of those already existing (Ivanchenko et al., 2008). N deficiency increases root sensitivity to ethylene and subsequent aerenchyma formation in maize seedlings (He et al., 1992), although ethylene production is reduced (Drew et al., 1989). Tari and Csiszár (2003) have found that, at $\mathrm{pH} 4.0$, nitrite treatment decreases the evolution of ethylene from the root apex but not from the base. Yang et al. (2011) reported that ethylene inhibits $\mathrm{NH}_{4}$-stimulated root hair branching, and that ACC $0.04 \mathrm{mM}$ antagonized the effect of $\mathrm{NH}_{4}$ by reducing hair branching from the $24 \%$ caused by $\mathrm{NH}_{4} \mathrm{NO}_{3}$ to only $5 \%$.
Nitrate can act as both a nutrient and a signal that regulates global gene expression in plant organs. Tian et al. (2009) found that, in the presence of high nitrate levels, roots ethylene production increases from roots as a result of an increase in the expression of the genes encoding ACS and ACO. They also showed that ethylene regulated nitratedependent root development by modulating the expression of nitrate transporters NRT1.1 and NRT2.1, thus demonstrating that ethylene signaling is involved in regulating nitrate uptake on the basis of changes in root elongation. The etr1-3 and ein2-1 mutants of ethylene signaling were insensitive to high nitrate concentrations. Lemaire et al. (2013) demonstrated that treatment with the ethylene precursor ACC induces a partial compensatory increase in $\mathrm{N}$ uptake, associated with the overexpression of the nitrate transporter genes, BnNRT2.1 and BnNRT1.1. Similar results were obtained by Leblanc et al. (2008) and Le Ny et al. (2013), who suggested that there is a linear correlation between root length and BnNRT2.1 expression levels in response to $10 \mu \mathrm{M}$ AVG or changes in nitrate availability. However, Leblanc et al. (2013) reported a decrease in BnNrt2.1 expression with an increase in ACC concentrations from 0.1 to $10 \mu \mathrm{M}$, thus suggesting that $B n N r t 2.1$ expression may adapt to changes in the absorbing surface of whole mature root by means of a still unknown regulatory mechanism. Leblanc et al. (2008) found that the rapid modulation of root elongation is more dependent on ethylene than on the nitrate signal: ACC treatment reduced $\mathrm{C}$ allocation and aspartate content in roots, thus showing that aspartate content correlates with changes in root length and shoot surface area. Canales et al. (2014) reported that up to $10 \%$ of the Arabidopsis genomes are $\mathrm{N}$ responsive, and approximately $7 \%$ in maize transcriptomes (Yang et al., 2011). N-induced root developmental plasticity is highly cell specific and finely regulated within the root (Gifford et al., 2008). Among the $\mathrm{N}$ responsive gene, five nitrate-responsive genes encoding $N R T 2.1, N R, H B 2, N i R$, and $H B 1$ are specifically regulated in the transition zone (Manoli et al., 2014; Trevisan et al., 2014). Trevisan et al. (2015) also reported that the transition zone is critical in sensing nitrate, which directly influences the transcript levels of a few genes and acts indirectly through NR.

Ethylene is also involved in regulating legume-rhizobial interactions: it influences the initial response of root hairs to Rhizobia bacteria exposure and the progression of infection into the cortex. Penmetsa and Cook (1997) found that the sickle mutant in Medicago truncatula is ethylene-insensitive and hyper-nodulated, and provided genetic support for the involvement of ethylene in regulating rhizobial symbiosis by encoding an ortholog of EIN2. Exogenous ethylene severely inhibits the formation and function of $\mathrm{N}$-fixation nodules on legume roots (Peters and Crist-Estes, 1989), possibly because the developmental effects of ethylene include the inhibition of cell division, DNA synthesis, and hook expansion (Apelbaum and Burg, 1972), and the induction of phytoalexin and extension biosynthesis (Ecker and Davis, 1987). Ethylene may act as a secondary signal regulating nodulation on the basis of the $\mathrm{N}$ status of the plant and as a negative feedback regulator of rhizobial infection (Oldroyd et al., 2001). Malamy and Ryan 
(2001) have suggested that the number of lateral roots is reduced in older root regions under conditions of $\mathrm{N}$ starvation.

\section{LEAF RESPONSES}

$\mathrm{N}$ deficiency also increases ethylene evolution in leaves as a consequence of stress (Legé et al., 1997). Over-irrigation of tomato plants induces $\mathrm{N}$ deficiency in leaves and greater ethylene biosynthesis, whereas the use of calcium nitrate to restore adequate $\mathrm{N}$ levels reduces ethylene evolution to control levels (Fiebig and Dodd, 2015). N starvation or deficiency also induces leaf senescence (particularly leaf yellowing), promotes the remobilization of nutrients from leaves to storage organs, and increases tissue sensitivity to ethylene. Many plants react to $\mathrm{N}$ starvation by activating the phenylpropanoid pathway and accumulating anthocyanins (Lea et al., 2007). In particular, low $\mathrm{N}$ levels in soils or growing media activates phenylalanine ammonia lyase (PAL, EC 4.3.1.5), the key enzyme of phenylpropanoid compounds. Various post-harvest studies have demonstrated that ethylene stimulates PAL activity, and it is known that the exposure of lettuce to ethylene generates russet spotting (i.e., brown spots on the mid-rib of head lettuce) (Hyodo et al., 1978; Ke and Saltveit, 1988).

There are no specific studies of the effects of the ethylene induced by $\mathrm{N}$ deficiency and the consequent PAL activity, but it is reasonable to assume that ethylene plays a pivotal role in this physiological behavior. Studies of Medicago sativa cell suspensions treated with 2-aminoindan-2-phosphonic acid (AIP), a potent inhibitor of PAL, have shown enhanced ethylene biosynthesis (Cvikrová et al., 1999), and similar results have been obtained in vitro callus cultures of red-fleshed apples with or without $\mathrm{N}$ supply in growth media. The absence of $\mathrm{N}$ strongly induces anthocyanin accumulation, thus demonstrating the direct role of $\mathrm{N}$ on phenylpropanoid activation. Under conditions of $\mathrm{N}$ deficiency or starvation, plant leaves activate a $\mathrm{N}$-recycling system in which $\mathrm{N}$ is recycled from phenylalanine by means of deamination to cinnamic acid, a reaction that is catalyzed by the PAL enzyme. Although it has not yet been established, it is likely that this futile cycle is under the control of ethylene. Ethylene biosynthesis is also affected by excess N. It is well known that the availability of high $\mathrm{N}$ levels induces vegetative growth, makes shoots more susceptible to insect attack (Davies et al., 2004), and causes greater damage due to abiotic stresses. The availability of $20 \mathrm{mM} \mathrm{N}$ in B. juncea plants increases ACS activity and ethylene evolution (Iqbal et al., 2015).

Plant photosynthesis and sugar biosynthesis have to balance any reduction in nitrates. As uptaken nitrate is reduced to ammonia under conditions of high $\mathrm{N}$ levels, plants cannot incorporate all of the reduced ammonia in amino acids, and this can generate stress leading to ethylene biosynthesis.

\section{FLOWER LIFE}

There are no specific studies linking $\mathrm{N}$ deficiency to ethylene evolution in flowers, but it has been reported that $\mathrm{N}$ deficiency increases ethylene biosynthesis and tissue sensitivity. Pre-harvest $\mathrm{N}$ deficiency affects the photosynthetic activity of plants, and the life of both growing and cut flowers (Druege, 2000). Under conditions of stress such as $\mathrm{N}$ efficiency, plants accelerate all of the physiological processes related to species dispersal: these usually include the induction of flowering in order to ensure dissemination.

No studies of flower senescence under conditions of $\mathrm{N}$ deficiency or excess have yet been carried out, but this would be interesting to investigate further.

\section{FRUIT RESPONSES}

$\mathrm{N}$ availability affects fruit development and quality, in particular low nitrogen content delay ripening and fruits are poor of sugars affecting negatively the overall quality. High nitrogen content usually induces rapid growth and fruits after harvest have faster senescence. Melons harvested from soil with deficient ( 0 or $50 \mathrm{~kg}$ $\mathrm{ha}^{-1}$ ) or excess $\mathrm{N}$ (165 $\mathrm{kg} \mathrm{ha}^{-1}$ ) levels have the same rate of ethylene biosynthesis. Ethylene production is lowest at the optimal fertilization dose of $110 \mathrm{~kg} \mathrm{ha}^{-1}$ at harvest, after 8 days of post-harvest storage at $10^{\circ} \mathrm{C}$, ethylene production decreased and no significant differences were found among treatments (Ferrante et al., 2008).

It has been found that the use of high, medium or low $\mathrm{N}$ fertilization does not affect ethylene production rates in peach trees, but high $\mathrm{N}$ levels delay the ripening of the fruit (Okamoto et al., 2001). No differences in ethylene production have been found in apples receiving soil and foliar $\mathrm{N}$, and controls with no supply of $\mathrm{N}$ (Wargo et al., 2004). There are few published information concerning $\mathrm{N}$ availability and ethylene production in horticultural crops, and so further studies are required in order to establish how $\mathrm{N}$ soil content affects ethylene production and the subsequent post-harvest performance of fruit.

Figure 2 shows a general view of how ethylene concentrations are affected by $\mathrm{N}$ levels in the different parts of plants.

\section{ETHYLENE INTERACTIONS WITH OTHER PHYTOHORMONES AT DIFFERENT LEVELS OF N AVAILABILITY}

Nitrogen levels considerably influence root architecture and crop production (Mohd-Radzman et al., 2013), and plants have efficient internal execution points to control $\mathrm{N}$ uptake, reduction and assimilation, and environmental NUE (Xu et al., 2012). Some recently published studies have begun to elucidate the link between ethylene signaling and $\mathrm{N}$ availability. Nitrate assimilation can take place directly in roots, and the assimilated nitrate can be stored in vacuoles or transferred to the aerial parts of a plant (Krapp, 2015) but, in many species, it preferentially occurs in shoots, where photosynthesis takes place and energy is easily available (Searles and Bloom, 2003).

However, a number of stresses can separate nitrate assimilation and photosynthesis by triggering nitrate allocation to roots. As hormonal action is an interdependent process, the 


\section{Increase ethylene}

\section{Decrease ethylene}

Fruits

- Low soil N content

- High soil N content

Leaves

- Low leaf $\mathrm{N}$ content

- Leaf yellowing induced by $\mathrm{N}$ deficiency
Roots

- High or low $\mathrm{N}$ content

- Hypoxia and low $\mathrm{N}$

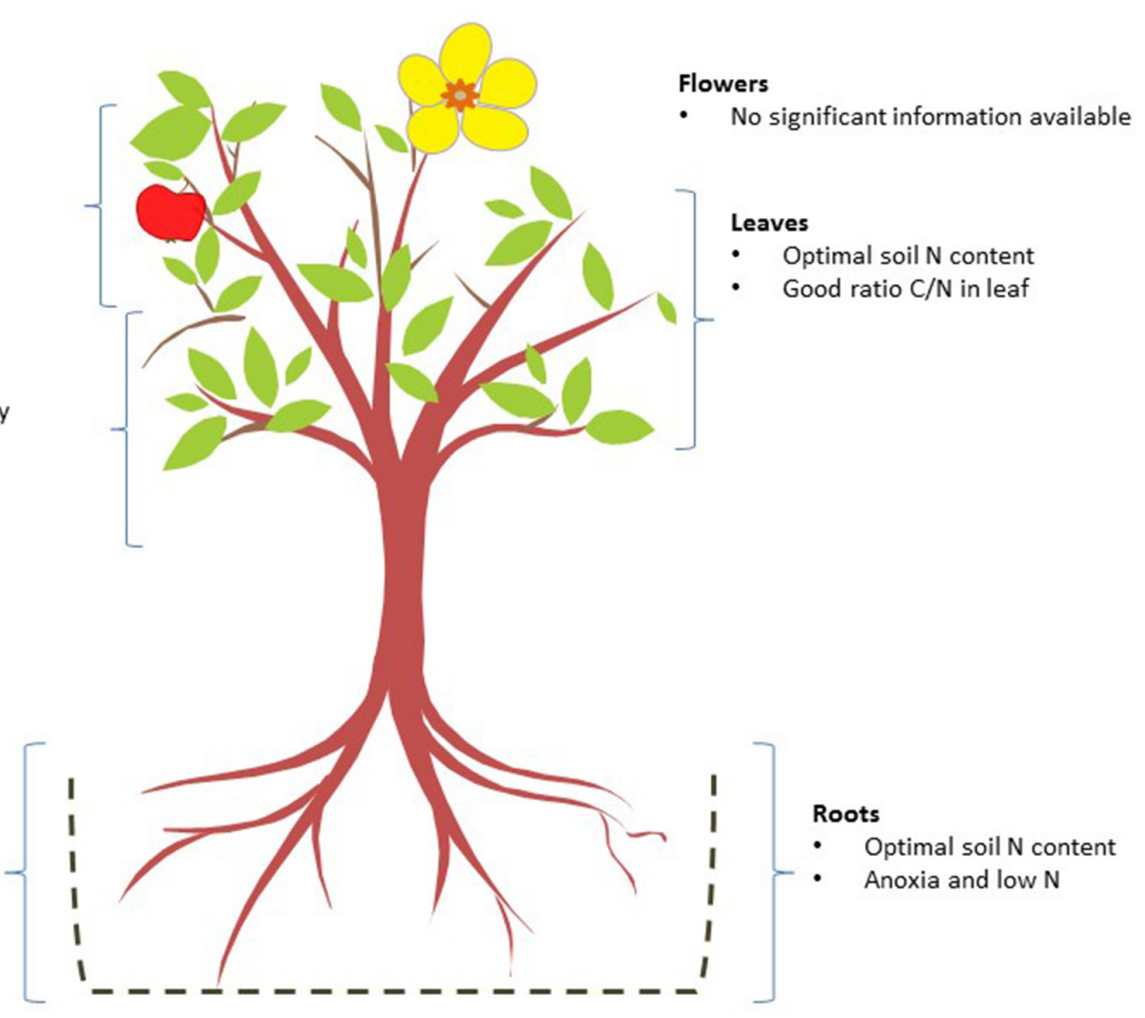

FIGURE 2 | Effects of nitrogen deficiency and excess on ethylene biosynthesis in different organs. The nitrogen levels that, alone or in combination with other factors, increase (left) or reduce ethylene biosynthesis (right) are shown for each organ.

action of ethylene at different $\mathrm{N}$ levels may be influenced by regulatory interactions between ethylene and other phytohormones. Genetic studies of $A$. thaliana by Swarup et al. (2007) have shown that ethylene-induced inhibition of root growth involves auxin, the presence of which significantly enhanced the inhibition of root cell elongation induced by the ethylene precursor ACC. It has also been reported the mutations in auxin transport or signaling components cause aberrant responses to ethylene, thus indicating the existence of cross-talk between the two phytohormones (Luschnig et al., 1998; Stepanova et al., 2005). Alonso et al. (2003) found that mutations in the auxin receptor TIR1 lead to ethylene-insensitive root growth phenotypes. Ethylene inhibits cell elongation by locally stimulating auxin biosynthesis and basipetal auxin transport toward the elongation zone; in mutants deficient in auxin perception or basipetal auxin transport, ethylene cannot activate the auxin response or regulate root growth (Rúžička et al., 2007).

Stress-initiated nitrate allocation to roots (SINAR) improves stress tolerance and decreases plant growth under non-stressed conditions via an ET/JA-NRT1.5/NRT1.8 signaling module (Zhang et al., 2014), which allows the regulation of nitrate assimilation at the level of the organ at which stresses initiate ET and JA signaling, which converges to EIN3/EIN3-Like1 (EIL1) in order to modulate ERF expression and up-regulate NRT1.8; ET and JA signaling mediates the down-regulation of NRT1.5 via EIN3/EIL1 and other unknown component(s). Krouk et al. (2010) demonstrated that, at low nitrate levels, mutations in the NRT1.1 nitrate transporter enhance auxin accumulation in lateral roots and lateral root growth. At low (but not high) nitrate levels, NRT1.1 represses lateral root growth by promoting the outward transport of basipetal auxin. Ma et al. (2014) showed that low $\mathrm{N}$ induces lateral root growth in Arabidopsis, and that this growth was dependent on the function of the auxin biosynthesis gene tryptophan aminotransferase related 2 (TAR2), which is induced under low $\mathrm{N}$ conditions. It has also been shown that molecules mediating auxin influx (AUX1, LAX2, LAX3) and efflux (PIN1, PIN2, PIN4, and PIN7) are transcriptionally regulated by $\mathrm{N}$ and/or C (Gutierrez et al., 2007; Li et al., 2011), and that most of these carriers are required for root development (Petrášek and Friml, 2009). It has been reported that jasmonic acid is a negative regulator of nodulation. Mi et al. (2008) reported that, in the presence of low $\mathrm{N}$ levels, the auxin, $\mathrm{CK}$ and nitric oxide (NO) signaling pathways are involved in regulating root elongation: an abundant $\mathrm{N}$ supply increases $\mathrm{CK}$ levels, but decreases auxin and NO levels in the roots of maize. The exogenous supply of CK increases ethylene production (Stenlid, 1982; Bertell et al., 1990). Nitrate-induced inhibition of root elongation in maize 
is significantly reversed by treating the roots with a NO donor (SNP) and IAA (Zhao et al., 2007). In the presence of high nitrate levels, endogenous levels of NO in the root apices of maize seedlings are much lower than those in apices grown in the presence of low nitrate levels. The inhibition of NO synthesis reduces root elongation in maize plants grown in a low-nitrate medium (Mi et al., 2008).

It has been reported that $\mathrm{N}$ supplementation induces $\mathrm{CK}$ accumulation in detached Helianthus annuus and Nicotiana tabacum leaves (Salama and Wareing, 1979; Singh et al., 1992). AtIPT3 (a gene involved in CK biosynthesis) is nitrate inducible, and atipt3 mutants reduce CK levels, thus indicating that AtIPT3 is a key determinant of nitrate-dependent CK biosynthesis (Miyawaki et al., 2004; Takei et al., 2004). The nitrate transporter NRT1.1 mediates the nitrate inducible expression of AtIPT3 (Liu et al., 1999; Ho et al., 2009), and Kiba et al. (2011) have found that $\mathrm{CK}$ represses the nitrate transporter gene and nitrate uptake regardless of plant N status. However, Rubio et al. (2009) and Krouk et al. (2011) have shown that CK also regulates the expression of $\mathrm{N}$ uptake- and assimilation-related genes, as well as root architecture (Werner et al., 2003; Higuchi et al., 2004). CK may function as a long-distance "root-to-shoot" signal related to $\mathrm{NO}_{3}{ }^{-}$supply (Takei et al., 2004; Sakakibara, 2006), and Ruffel et al. (2011) found that it is a crucial component of a root-shootroot signaling mechanism that is involved in conveying a plant's $\mathrm{NO}_{3}{ }^{-}$status, thus enabling a compensatory increase in lateral root growth in $\mathrm{NO}_{3}{ }^{-}$-rich zones of a root system foraging for $\mathrm{N}$ resources in a heterogeneous $\mathrm{N}$ environment.

Signora et al. (2001) showed that both ABA-insensitive mutants (abi4-1, abi4-2, and abi5-1) and ABA-deficient mutants (aba1-1, aba2-3, aba2-4, and aba3-2) are less sensitive to the inhibitory effects of high nitrate levels, and the study of the Medicago truncatula latd mutant by Yendrek et al. (2010) provided another line of evidence supporting a link between $\mathrm{ABA}$ and $\mathrm{N}$ signaling. The latd mutant is characterized by severe defects in root meristem maintenance and root growth, and its primary root growth is insensitive to nitrate; the LATD gene encodes a transporter belonging to the NRT1 (PTR) family, and is rescued by exogenous ABA (Bright et al., 2005; Liang et al., 2007).

Sun et al. (2015) have found that the NR pathway in Oryza sativa generates $\mathrm{NO}$, which improves $\mathrm{N}$ acquisition capacity by increasing the initiation of lateral roots and the uptake of inorganic $\mathrm{N}$, a strategy that allows the plants to adapt to a fluctuating nitrate supply and increase NUE. Liu et al. (2010) reported that ethylene induces NO formation in A. thaliana. $\mathrm{N}$ availability affects ethylene biosynthesis and signaling, which further increases $\mathrm{N}$ uptake and transport to enhance plant growth. The effect of ethylene on root architecture increases $\mathrm{N}$ absorption and influences $\mathrm{N}$ transport-related genes. It has been shown that the action of ethylene on $\mathrm{N}$ uptake or root growth is not independent of other phytohormones as low nitrate levels also increase $\mathrm{CK}$, auxin, ABA and NO. CK increases the production of ethylene, which acts in coordination with auxin in order to ensure root growth and lateral root formation. These hormones are influenced by $\mathrm{N}$ and affect root growth but, as their cross-talk allows them to acquire $\mathrm{N}$ in the case of a limited supply, there is a need to verify whether ethylene functions in coordination with these hormones under the same conditions. Inhibiting these phytohormones under condition of limited $\mathrm{N}$ availability could provide insights into their mechanism of action, and enable the use of ethylene as a means of increasing plant NUE, avoiding $\mathrm{N}$ wastage, and preventing environmental pollution.

It is widely recognized that a high ethylene concentration is a potent inhibitor of nodule development in plants (Lee and LaRue, 1992; Sun et al., 2006; Gresshoff et al., 2009). Ferguson et al. (2011) have recently reported that there is a close relationship between gibberellin, ethylene and nodulation in Pisum sativum: the application of the ethylene precursor ACC significantly reduces the number of nodules and root and shoot length in wild-type NA plants, whereas treatment with the ethylene biosynthesis inhibitor AVG increases the number of nodules to 36 times the number formed on gibberellindeficient mutant na-1 plants. They also suggested that ethylene biosynthesis genes (PsACS1 and PsACO1) were decreased in na1 roots, but the fact that there was no significant change in PsACO1 in the roots of na-1 plants during nodule formation indicates that ethylene plays a role in nodulation. However, there is a need for further experiments aimed at investigations the relationships between ethylene and other hormones in nodule formation.

The use of methyl jasmonate restrains nodulation in Lotus japonicas, including infection thread formation and NIN gene expression in wild-type plants and the hyper-nodulated har 1 mutant (Nakagawa and Kawaguchi, 2006). It has also been found that nodulation is inhibited in Medicago truncatula cultured in a growth medium containing JA, and that the number of NIN transcripts is larger in transgenic than in wild-type plants. Ethylene signaling negatively regulates the early stage of nodule development, including infection thread formation and the emergence of nodule primordia (Penmetsa and Cook, 1997).

\section{CONCLUSION AND FUTURE PROSPECTS}

Nitrogen availability has a strong influence on ethylene biosynthesis and signaling, and plants have different metabolic responses to optimal and stressful conditions. As $\mathrm{N}$ is a core mineral nutrient, larger amounts of $\mathrm{N}$ improve crop productivity, increasing NUE. Modulating ethylene availability should have a positive effect on sustainable development by reducing the wastage of applied $\mathrm{N}$ and increasing environmental protection. In order to maximize the genetic potential of $\mathrm{N}$ use, it is important to focus research on clarifying the interactions of $\mathrm{N}$, ethylene and other hormones in order to be able to use more $\mathrm{N}$ under $\mathrm{N}$-deficient conditions without affecting environmental safety.

\section{SUPPLEMENTARY MATERIAL}

The Supplementary Material for this article can be found online at: http://journal.frontiersin.org/article/10.3389/fpls.2015.00927 


\section{REFERENCES}

Afifi, M., El-Kereamy, A., Legrand, V., Chervin, C., Monje, M. C., Nepveu, F., et al. (2003). Control of anthocyanin biosynthesis pathway gene expression by eutypine, a toxin from Eutypa lata, in grape cell tissue cultures. J. Plant Physiol. 160, 971-975. doi: 10.1078/0176-1617-00921

Alonso, J. M., Stepanova, A. N., Solano, R., Wisman, E., Ferrari, S., Ausubel, F. M. et al. (2003). Five components of the ethylene-response pathway identified in a screen for weak ethylene-insensitive mutants in Arabidopsis. Proc. Natl. Acad. Sci. U.S.A. 100, 2992-2997. doi: 10.1073/pnas.0438070100

Apelbaum, A., and Burg, S. P. (1972). Effect of ethylene on cell division and deoxy ribonucleic acid synthesis in Pisum sativum. Plant Physiol. 50, 117-124. doi: 10.1104/pp.50.1.125

Arteca, R. N., and Arteca, J. N. (2007). Heavy-metal-induced ethylene production in Arabidopsis thaliana. J. Plant Physiol. 164, 1480-1488. doi: 10.1016/j.jplph.2006.09.006

Balazadeh, S., Schildhauer, J., Araújo, W. L., Munnè-Bosch, S., Fernie, A. R., Proost, S., et al. (2014). Reversal of senescence by $\mathrm{N}$ resupply to $\mathrm{N}$-starved Arabidopsis thaliana: transcriptomic and metabolomic consequences. J. Exp. Bot. 65, 3975-3992. doi: 10.1093/jxb/eru119

Bertell, G., Bolander, E., and Eliasson, L. (1990). Factors increasing ethylene production enhance the sensitivity of root growth to auxins. Physiol. Plant. 79, 255-258. doi: 10.1034/j.1399-3054.1990.790207.x

Bi, Y. M., Wang, R. L., Zhu, T., and Rothstein, S. J. (2007). Global transcription profiling reveals differential responses to chronic nitrogen stress and putative nitrogen regulatory components in Arabidopsis. BMC Genomics 8:821. doi: 10.1186/1471-2164-8-281

Bright, R. A., Medina, M. J., Xu, X., Perez-Oronoz, G., Wallis, T. R., Davis, X. M., et al. (2005). Incidence of adamantane resistance among influenza A (H3N2) viruses isolated worldwide from 1994 to 2005: a cause for concern. Lancet 366, 1175-181. doi: 10.1016/S0140-6736(05)67338-2

Buer, C. S., Wasteneys, G. O., and Masle, J. (2003). Ethylene modulates root-wave responses in Arabidopsis. Plant Physiol. 132, 1085-1096. doi: $10.1104 /$ pp. 102.019182

Caba, J. M., Recalde, L., and Ligero, F. (1998). Nitrate-induced ethylene biosynthesis and the control of nodulation in alfalfa. Plant Cell Environ. 21, 87-93. doi: 10.1046/j.1365-3040.1998.00242.x

Cai, H., Xie, W., and Lian, H. X. (2013). Comparative analysis of differentially expressed genes in rice under nitrogen and phosphorus starvation stress conditions. Plant Mol. Biol. Rep. 31, 160-173. doi: 10.1007/s11105-012-0485-8

Canales, J., Moyano, T. C., Villarroel, E., and Gutiérrez, R. A. (2014). Systems analysis of transcriptome data provides new hypotheses about Arabidopsis root response to nitrate treatments. Front. Plant Sci. 5:22. doi: 10.3389/fpls.2014.00022

Christians, M. J., Gingerich, D. J., Hansen, M., Binder, B. M., Kieber, J. J., and Vierstra, R. D. (2009). The BTB ubiquitin ligases ETO1, EOL1 and EOL2 act collectively to regulate ethylene biosynthesis in Arabidopsis by controlling type-2 ACC synthase levels. Plant J. 57, 332-345. doi: 10.1111/j.1365313X.2008.03693.x

Clark, D. G., Gubrium, E. K., Barrett, J. E., Nell, T. A., and Klee, H. J. (1999). Root formation in ethylene-insensitive plants. Plant Physiol. 121, 53-60. doi: 10.1104/pp.121.1.53

Crawford, N. M. (1995). Nitrate: nutrient and signal for plant growth. Plant Cell 7, 859-868. doi: 10.1105/tpc.7.7.859

Cvikrová, M., Binarová, P., Eder, J., Vágner, M., Hrubcová, M., Zoń, J., et al. (1999). Effect of inhibition of phenylalanine ammonia-lyase activity on growth of alfalfa cell suspension culture: alterations in mitotic index, ethylene production, and contents of phenolics, cytokinins and polyamines. Physiol. Plant. 107, 329-337. doi: 10.1034/j.1399-3054.1999.100310.x

Davies, F. T., He, C., Chau, A., Heinz, K. M., and Cartmill, A. D. (2004). Fertility affects susceptibility of chrysanthemum to cotton aphids: influence on plant growth, photosynthesis, ethylene evolution, and herbivore abundance. J. Am. Soci. Hortic. Sci. 129, 344-353.

Di Baccio, D., Ederli, L., Marabottini, R., Badiani, M., Francini, A., Nali, C., et al. (2012). Similar foliar lesions but opposite hormonal patterns in a tomato mutant impaired in ethylene perception and its near isogenic wild type challenged with ozone. Environ. Exp. Bot. 75, 286-297. doi: 10.1016/j.envexpbot.2011.08.001
Dorling, S. L., Leung, S., Anderson, C. W. N., Albert, N. W., and McManus, M. T. (2011). Changes in 1-aminocyclopropane-1-carboxlate (ACC) oxidase expression and enzyme activity in response to excess manganese in white clover (Trifolium repens L.). Plant Physiol. Biochem. 49, 1013-1019. doi: 10.1016/j.plaphy.2011.04.007

Drew, M. C., He, C. J., and Morgan, P. W. (1989). Decreased ethylene biosynthesis, and induction of aerenchyma, by nitrogen-starvation or phosphate-starvation in adventitious roots of Zea mays. Plant Physiol. 91, 266-271. doi: 10.1104/pp.91.1.266

Drew, M. C., He, C. J., and Morgan, P. W. (2000). Programmed cell death and aerenchyma formation in roots. Trends Plant Sci. 5, 123-127. doi: $10.1016 /$ S1360-1385(00)01570-3

Druege, U. (2000). Influence of pre-harvest nitrogen supply on post-harvest behaviour of ornamentals: importance of carbohydrate status, photosynthesis and plant hormones. Gartenbauwissenschaft 65, 53-64.

Ecker, J. R., and Davis, R. W. (1987). Plant defense genes are regulated by ethylene. Proc. Natl. Acad. Sci. U.S.A. 84, 5202-5206. doi: 10.1073/pnas.84.15.5202

El-Kereamy, A., Chervin, C., and Roustan, J. (2003). Exogenous ethylene stimulates the long-term expression of genes related to anthocyanin biosynthesis in grape berries. Physiol. Plant. 119, 175-182. doi: 10.1034/j.1399-3054.2003.00165.x

Ferguson, B. J., Foo, E., Ross, J. J., and Reid, J. B. (2011). Relationship between gibberellin, ethylene and nodulation in Pisum sativum. New Phytol. 189, 829842. doi: 10.1111/j.1469-8137.2010.03542.x

Ferrante, A., Spinardi, A., Maggiore, T., Testoni, A., and Gallina, P. M. (2008). Effect of nitrogen fertilization levels on melon fruit quality at the harvest time and during storage. J. Sci. Food Agric. 88, 707-713. doi: 10.1002/jsfa.3139

Fiebig, A., and Dodd, I. C. (2015). Inhibition of tomato shoot growth by overirrigation is linked to nitrogen deficiency and ethylene. Physiol. Plant. doi: 10.1111/ppl.12343 [Epub ahead of print].

Forde, B. G. (2014). Nitrogen signalling pathways shaping root system architecture: an update. Curr. Opin. Plant Biol. 21, 30-36. doi: 10.1016/j.pbi.2014.06.004

Forde, B. G., and Lea, P. J. (2007). Glutamate in plants: metabolism, regulation, and signalling. J. Exp. Bot. 58, 2339-2358. doi: 10.1093/jxb/erm121

Fowler, S., and Thomashow, M. F. (2002). Arabidopsis transcriptome profiling indicates that multiple regulatory pathways are activated during cold acclimation in addition to the $\mathrm{CBF}$ cold response pathway. Plant Cell 14, 1675-1690. doi: 10.1105/tpc.003483

Gastal, F., and Lemaire, G. (2002). N uptake and distribution in crops: an agronomical and ecophysiological perspective. J. Exp. Bot. 53, 789-799. doi: 10.1093/jexbot/53.370.789

Gifford, M. L., Dean, A., Gutierrez, R. A., Coruzzi, G. M., and Birnbaum, K. D. (2008). Cell-specific nitrogen responses mediate developmental plasticity. Proc. Natl. Acad. Sci. U.S.A. 105, 803-808. doi: 10.1073/pnas.0709559105

Gresshoff, P. M., Dasharath, L., Pick-Kuen, C., Bandana, B., Qunyi, J., Dugald, R., et al. (2009). Genetic analysis of ethylene regulation of legume nodulation. Plant Signl. Behav. 4, 818-823. doi: 10.4161/psb.4.9.9395

Gutierrez, R. A., Lejay, L. V., Dean, A., Chiaromonte, F., Shasha, D. E., and Coruzzi, G. M. (2007). Qualitative network models and genome-wide expression data define carbon/nitrogen-responsive molecular machines in Arabidopsis. Genome Biol. 8, R7. doi: 10.1186/gb-2007-8-1-r7

Han, L., Li, G. L., Yang, K. Y., Mao, G., Wang, R., Liu, Y., et al. (2010). Mitogen-activated protein kinase 3 and 6 regulate Botrytis cinerea induced ethylene production in Arabidopsis. Plant J. 64, 114-127. doi: 10.1111/j.1365313X.2010.04318.x

He, C., Davies, F. T. J., and Lacey, R. E. (2009). Ethylene reduces gas exchange and growth of lettuce plants under hypobaric and normal atmospheric conditions. Physiol. Plant. 135, 258-271. doi: 10.1111/j.1399-3054.2008.01190.x

He, C. J., Morgan, P. W., and Drew, M. C. (1992). Enhanced sensitivity to ethylene in nitrogen- or phosphate-starved roots of Zea mays L. during aerenchyma formation. Plant Physiol. 98, 137-142. doi: 10.1104/pp.98.1.137

Higuchi, M., Pischke, M. S., Mahonen, A. P., Miyawaki, K., Hashimoto, Y. Seki, M., et al. (2004). In planta functions of the Arabidopsis cytokinin receptor family. Proc. Natl. Acad. Sci. U.S.A. 101, 8821-8826. doi: 10.1073/pnas.0402 887101

Hinz, M., Wilson, I. W., Yang, J., Buerstenbinder, K., Llewellyn, D., Dennis, E. S., et al. (2010). Arabidopsis RAP2.2: an ethylene response transcription factor that is important for hypoxia survival. Plant Physiol. 153, 757-772. doi: 10.1104/pp.110.155077 
Hirel, B., Le Goulis, J., Ney, B., and Gallais, A. (2007). The challenge of improving nitrogen use efficiency in crop plants: towards a more central role for genetic variability and quantitative genetics within integrated approaches. J. Exp. Bot. 58, 2369-2387. doi: 10.1093/jxb/erm097

Ho, C. H., Lin, S. H., Hu, H. C., and Tsay, Y. F. (2009). CHL1 functions as a nitrate sensor in plants. Cell 138, 1184-1194. doi: 10.1016/j.cell.2009.07.004

Horchani, F., Aschi-Smiti, S., and Brouquisse, R. (2010). Involvement of nitrate reduction in the tolerance of tomato (Solanum lycopersicum L.) plants to prolonged root hypoxia. Acta Physiol. Plant. 32, 1113-1123. doi: 10.1007/s11738-010-0503-0

Hruz, T., Laule, O., Szabo, G., Wessendorp, F., Bleuler, S., Oertle, L., et al. (2008). Genevestigator v3: a reference expression database for the meta-analysis of transcriptomes. Adv. Bioinformatics 2008, 420747. doi: 10.1155/2008/420747

Huang, D. W., Sherman, B. T., and Lempicki, R. A. (2009). Systematic and integrative analysis of large gene lists using DAVID Bioinformatics Resources. Nat. Protoc. 4, 44-57. doi: 10.1038/nprot.2008.211

Hyodo, H., Kuroda, H., and Yang, S. F. (1978). Induction of phenylalanine ammonia-lyase and increase in phenolics in lettuce leaves in relation to the development of russet spotting caused by ethylene. Plant Physiol. 62, 31-35. doi: 10.1104/pp.62.1.31

Inaba, A., Xuejun, L., Yokotani, N., Yamane, M., Lu, W. J., Nakano, R., et al. (2007). Differential feedback regulation of ethylene biosynthesis in pulp and peel tissues of banana fruit. J. Exp. Bot. 58, 1047-1057. doi: 10.1093/jxb/erl265

Iqbal, N., Khan, N. A., Nazar, R., and Silva, J. A. (2012). Ethylene-stimulated photosynthesis results from increased nitrogen and sulfur assimilation in mustard types that differ in photosynthetic capacity. Environ. Exp. Bot. 78, 84-90. doi: 10.1016/j.envexpbot.2011.12.025

Iqbal, N., Nazar, R., Syeed, S., Massod, A., and Khan, N. A. (2011). Exogenouslysourced ethylene increases stomatal conductance, photosynthesis, and growth under optimal and deficient nitrogen fertilization in mustard. J. Exp. Bot. 62, 4955-4963. doi: 10.1093/jxb/err204

Iqbal, N., Trivellini, A., Masood, A., Ferrante, A., and Khan, N. A. (2013). Current understanding on ethylene signaling in plants: the influence of nutrient availability. Plant Physiol. Biochem. 73, 128-138. doi: 10.1016/j.plaphy.2013.09.011

Iqbal, N., Umar, S., and Khan, N. A. (2015). Nitrogen availability regulates proline and ethylene production and alleviates salinity stress in mustard (Brassica juncea). J. Plant Physiol. 178, 84-91. doi: 10.1016/j.jplph.2015.02.006

Ivanchenko, M. G., Muday, G. K., and Dubrovsky, J. G. (2008). Ethylene-auxin interactions regulate lateral root initiation and emergence in Arabidopsis thaliana. Plant J. 55, 335-347. doi: 10.1111/j.1365-313X.2008.03528.x

Jibran, R., Hunter, D. A., and Dijkwel, P. P. (2013). Hormonal regulation of leaf senescence through integration of developmental and stress signals. Plant Mol. Biol. 82, 547-561. doi: 10.1007/s11103-013-0043-2

Jin, J., Watt, M., and Mathesius, U. (2012). The autoregulation gene SUNN mediates changes in root organ formation in response to nitrogen through alteration of shoot-to-root auxin transport. Plant Physiol. 159, 489-500. doi: 10.1104/pp.112.194993

Jung, J. Y., Shin, R., and Schachtman, D. P. (2009). Ethylene mediates response and tolerance to potassium deprivation in Arabidopsis. Plant Cell 21, 607-621. doi: 10.1105/tpc.108.063099

Kaack, K., and Pedersen, H. L. (2014). Effects of potassium, phosphorus and nitrogen fertilization on endogenous ethylene and quality characteristics of apples (Malus domestica L.). J. Plant Nutr. 37, 1148-1155. doi: 10.1080/01904167.2013.868484

Ke, D., and Saltveit, M. E. (1988). Plant hormone interaction and phenolic metabolism in the regulation of russet spotting in ice berg lettuce. Plant Physiol. 88, 1136-1140. doi: 10.1104/pp.88.4.1136

Khan, M. I. R., and Khan, N. A. (2014). Ethylene reverses photosynthetic inhibition by nickel and zinc in mustard through changes in PS II activity, photosynthetic nitrogen use efficiency, and antioxidant metabolism. Protoplasma 251, 10071019. doi: 10.1007/s00709-014-0610-7

Khan, M. I. R., Nazir, F., Asgher, M., Per, T. S., and Khan, N. A. (2015). Selenium and sulfur influence ethyleneformation and alleviate cadmiuminduced oxidative stress by improving prolineand glutathione production in wheat. J. Plant Physiol. 173, 9-18. doi: 10.1016/j.jplph.2014.09.011

Khan, N. A., Mir, M. R., Nazar, R., and Singh, S. (2008). The application of ethephon (an ethylene releaser) increases growth, photosynthesis and nitrogen accumulation in mus-tard (Brassica juncea L.) under high nitrogen levels. Plant Biol. 10, 534-538. doi: 10.1111/j.1438-8677.2008.00054.x

Kiba, T., Kudo, T., Kojima, M., and Sakakibara, H. (2011). Hormonal control of nitrogen acquisition: roles of auxin, abscisic acid, and cytokinin. J. Exp. Bot. 62, 1399-1409. doi: 10.1093/jxb/erq410

Kim, H. J., Lynch, J. P., and Brown, K. M. (2008). Ethylene insensitivity impedes a subset of responses to phosphorus deficiency in tomato and petunia. Plant Cell Environ. 31, 1744-1755. doi: 10.1111/j.1365-3040.2008.01886.x

Kim, M. A., Ruzickaa, D., Shinb, R., and Schachtman, D. P. (2012). The Arabidopsis AP2/ERF transcription factor RAP2.11 modulates plant response to lowpotassium conditions. Mol. Plant 5, 1042-1057. doi: 10.1093/mp/sss003

Krapp, A. (2015). Plant nitrogen assimilation and its regulation: a complex puzzle with missing pieces. Curr. Opin. Plant Biol. 25, 115-122. doi: 10.1016/j.pbi.2015.05.010

Krouk, G., Crawford, N. M., Coruzzi, G. M., and Tsay, Y. F. (2010). Nitrate signaling: adaptation to fluctuating environments. Curr. Opin. Plant Biol. 13, 265-272. doi: 10.1016/j.pbi.2009.12.003

Krouk, G., Lacombe, B., Bielach, A., Perrine-Walker, F., Malinska, K., Mounier, E., et al. (2011). Nitrate-regulated auxin transport by NRT1.1 defines a mechanism for nutrient sensing in plants. Dev. Cell 18, 1-11. doi: 10.1016/j.devcel.2010.05.008

Kuiper, D. (1988). Growth responses of Plantago major L. ssp. pleiosperma (Pilger) to changes in mineral supply evidence for regulation by cytokinins. Plant Physiol. 87, 555-557. doi: 10.1104/pp.87.3.555

Kuiper, P. J. C., Kuiper, D., and Schuit, J. (1989). "Root functioning under stress conditions: an introduction," in Structural and Functional Aspects of Transport in Roots Development, Vol. 36, eds B. C. Loughamn, O. Gašparíková, and J. Kolek (Dordrecht: Springer), 209-213.

Le, J., Vandenbusche, F., Van Der Streaten, D., and Verbelen, J. P. (2001). In early response of Arabidopsis roots to ethylene, cell elongation is up- and downregulated and uncoupled from differentiation. Plant Physiol. 125, 519-522. doi: 10.1104/pp.125.2.519

Le Ny, F., Leblanc, A., Beauclair, P., Deleu, C., and Le Deunff, E. (2013). In low transpiring conditions, nitrate and water fluxes for growth of $B$. napus plantlets correlate with changes in BnNrt2.1 and BnNrt1.1 nitrate transporters expression. Plant Signal. Behav. 8, e22902. doi: 10.4161/psb.22902

Lea, P. J., and Miflin, B. J. (2003). Glutamate synthase and the synthesis of glutamate in plants. Plant Physiol. Biochem. 41, 555-564. doi: 10.1016/S09819428(03)00060-3

Lea, U. S., Slimestad, R., Smedvig, P., and Lillo, C. (2007). Nitrogen deficiency enhances expression of specific MYB and bHLH transcription factors and accumulation of end products in the flavonoid pathway. Planta 225, 1245-1253. doi: 10.1007/s00425-006-0414-x

Leblanc, A., Renault, H., Lecourt, J., Etienne, P., Deleu, C., and Le Deunff, E. (2008). Elongation changes of exploratory and root hair systems induced by AVG and ACC affect nitrate uptake and BnNrt2.1 and BnNrt1.1 gene expression in oil seed Rape. Plant Physiol. 146, 1028-1040. doi: 10.1104/pp.107.109363

Leblanc, A., Segura, R., Deleu, C., and Le, D. E. (2013). In low transpiring conditions, uncoupling the BnNrt2.1 and BnNrt1.1 NO3 - transporters by glutamate treatment reveals the essential role of BnNRT2.1 for nitrate uptake and the nitrate-signalling cascade during growth. Plant Signal. Behav. 8, e22904. doi: $10.4161 /$ psb.22904

Lee, K. H., and LaRue, T. A. (1992). Exogenous ethylene inhibits nodulation of Pisum sativum L. cv Sparkle. Plant Physiol. 100, 1759-1763. doi: 10.1104/pp.100.4.1759

Legé, K. E., Cothren, J. T., and Morgan, P. W. (1997). Nitrogen fertility and leaf age effect on ethylene production of cotton in a controlled environment. Plant Growth Regul. 22, 23-28. doi: 10.1023/A:1005854625641

Lemaire, L., Deleu, C., and Le, D. E. (2013). Modulation of ethylene biosynthesis by ACC and AIB reveals a structural and functional relationship between the K15NO3 uptake rate and root absorbing surfaces. J. Exp. Bot. 64, 2725-2737. doi: $10.1093 / \mathrm{jxb} / \mathrm{ert} 124$

Li, B., Li, Q., Su, Y., Chen, H. A. O., Xiong, L., Mi, G., et al. (2011). Shootsupplied ammonium targets the root auxin influx carrier AUX1 and inhibits lateral root emergence in Arabidopsis. Plant Cell Environ. 34, 933-946. doi: 10.1111/j.1365-3040.2011.02295.X

Li, Y. S., Mao, X. T., Tian, Q. Y., Li, L. H., and Zhang, W. H. (2009). Phosphorus deficiency induced reduction in root hydraulic conductivity is 
mediated by ethylene in Medicago falcate. Environ. Exp. Bot. 67, 172-177. doi: 10.1016/j.envexpbot.2009.05.013

Liang, G., He, H., and Yu, D. (2012). Identification of nitrogen starvationresponsive microRNAs in Arabidopsis thaliana. PLoS ONE 7:e48951. doi: 10.1371/journal.pone.0048951

Liang, Y., Mitchell, D. M., and Harris, J. M. (2007). Abscisic acid rescues the root meristem defects of the Medicago truncatula latd mutant. Dev. Biol. 304, 297-307. doi: 10.1016/j.ydbio.2006.12.037

Licausi, F., Kosmacz, M., Weits, D. A., Giuntoli, B., Giorgi, F. M., Voesenek, L. A., et al. (2011). Oxygen sensing in plants is mediated by an $\mathrm{N}$ end rule pathway for protein destabilization. Nature 479, 419-422. doi: 10.1038/nature10536

Licausi, F., van Dongen, J. T., Giuntoli, B., Novi, G., Santaniello, A., Geigenberger, P., et al. (2010). HRE1 and HRE2, two hypoxia-inducible ethylene response factors, affect anaerobic responses in Arabidopsis thaliana. Plant J. 62, 302-315. doi: 10.1111/j.1365-313X.2010.04149.x

Limami, A. N., Diab, H., and Lothier, J. (2014). Nitrogen metabolism in plants under low oxygen stress. Planta 239, 531-541. doi: 10.1007/s00425-013-2015-9

Lin, Z., Zhong, S., and Grierson, D. (2009). Recent advances in ethylene research. J. Exp. Bot. 60, 3311-3336. doi: 10.1093/jxb/erp204

Liu, H., Wang, Y., Xu, J., Su, T., Liu, G., and Ren, D. (2008). Ethylene signalling is required for the acceleration of cell death induced by activation of AtMEK5 in Arabidopsis. Cell Res. 18, 422-432. doi: 10.1038/cr.2008.29

Liu, J., Liu, G., Hou, L., and Liu, X. (2010). Ethylene-induced nitric oxide production and stomatal closure in Arabidopsis thaliana depending on changes in cytosolic pH. Chin. Sci. Bull. 55, 2403-2409. doi: 10.1007/s11434-010-4033-3

Liu, K. H., Huang, C. Y., and Tsay, Y. F. (1999). CHL1 is a dual-affinity nitrate transporter of Arabidopsis involved in multiple phases of nitrate uptake. Plant Cell 11, 865-874. doi: 10.2307/3870820

Liu, P., Sun, F., Gao, R., and Dong, H. (2012). RAP2.6L overexpression delays water logging induced premature senescence by increasing stomatal closure more than antioxidant enzyme activity. Plant Mol. Biol. 79, 609-622. doi: 10.1007/s11103-012-9936-8

Luo, Q. L., Mittal, A., Jia, F., and Rock, C. D. (2012). An autoregulatory feedback loop involving PAP1 and TAS4 in response to sugars in Arabidopsis. Plant Mol. Biol. 80, 117-129. doi: 10.1007/s11103-011-9778-9

Luschnig, C., Gaxiola, R., Grisafi, P., and Fink, G. (1998). EIR1, a root-specific protein involved in auxin transport, is required for gravitropism in Arabidopsis thaliana. Genes Dev. 12, 2175-2187. doi: 10.1101/gad.12.14.2175

Lynch, J. P. (2007). Roots of the second green revolution. Aust. J. Bot. 55, 493-512. doi: 10.1071/BT06118

Lyzenga, W. J., Booth, J. K., and Stone, S. L. (2012). The Arabidopsis RINGtype E3 ligase XBAT32 mediates the proteasomal degradation of the ethylene biosynthetic enzyme, 1-aminocyclopropane-1-carboxylate synthase 7. Plant J. 71, 23-34. doi: 10.1111/j.1365-313X.2012.04965.x

Ma, W., Li, J., Qu, B., He, X., Zhao, X., Li, B., et al. (2014). Auxin biosynthetic gene TAR2 is involved in low nitrogen-mediated reprogramming of root architecture in Arabidopsis. Plant J. 78, 70-79. doi: 10.1111/tpj.12448

Malamy, J. E., and Ryan, K. S. (2001). Environmental regulation of lateral root initiation in Arabidopsis. Plant Physiol. 127, 899-909. doi: 10.1104/pp.010406

Manoli, A., Begheldo, M., Genre, A., Lanfranco, L., Trevisan, S., and Quaggiotti, S. (2014). NO homeostasis is a key regulator of early nitrate perception and root elongation in maize. J. Exp. Bot. 65, 185-200. doi: 10.1093/jxb/ert358

Martin, T., Oswald, O., and Graham, I. A. (2002). Arabidopsis seedling growth, storage lipid mobilization, and photosynthetic gene expression are regulated by carbon: nitrogen availability. Plant Physiol. 128, 472-481. doi: 10.1104/pp.010475

Mei, H. S., and Thimann, K. V. (1984). The relation between nitrogen deficiency and leaf senescence. Physiol. Plant. 62, 157-161. doi: 10.1111/j.13993054.1984.tb00364.x

Mi, G., Chen, F., and Zhang, F. (2008). Multiple signaling pathways controls nitrogen-mediated root elongation in maize. Plant Signal. Behav. 3, 1030-1032. doi: $10.4161 /$ psb. 6800

Mir, M. R. (2002). Physiological Significance of Ethrel (2- Chloroethyl Phosphonic Acid) and Nitrogen in Relation to Growth and Metabolism of Mustard Under Irrigatedand Non-Irrigated Conditions. Ph. D. thesis, Aligarh Muslim University, Aligarh.

Misyura, M., Guevara, D., Subedi, S., Hudson, D., McNicholas, P. D., Colasanti, J., et al. (2014). Nitrogen limitation and high density responses in rice suggest a role for ethylene under high density stress. BMC Genomics 15:681. doi: 10.1186/1471-2164-15-681

Miyawaki, K., Matsumoto-Kitano, M., and Kakimoto, T. (2004). Expression of cytokinin biosynthetic isopentenyltransferase genes in Arabidopsis: tissue specificity and regulation by auxin, cytokinin, and nitrate. Plant J. 37, 128-138. doi: 10.1046/j.1365-313X.2003.01945.x

Mohd-Radzman, N. A., Djordjevic, M. A., and Imin, N. (2013). Nitrogen modulation of legume root architecture signaling pathways involves phytohormones and small regulatory molecules. Front. Plant Sci. 4:385. doi: $10.3389 /$ fpls. 2013.00385

Morard, P., Silvestre, J., Lacoste, L., Caumes, E., and Lamaze, T. (2004). Nitrate uptake and nitrite release by tomato roots in response to anoxia. J. Plant Physiol. 161, 855-865. doi: 10.1016/j.jplph.2003.11.003

Mur, L. A. J., Mandon, J., Persijn, S., Cristescu, S. M., Moshkov, I. E., Novikova, G. V., et al. (2012). Nitric oxide in plants: an assessment of the current state of knowledge. AoB Plants 5, pls052. doi: 10.1093/aobpla/pls052

Nakagawa, T., and Kawaguchi, M. (2006). Shoot-applied MeJA suppresses root nodulation in Lotus japonicus. Plant Cell Physiol. 47, 176-180. doi: $10.1093 / \mathrm{pcp} / \mathrm{pci} 222$

Nukui, N., Ezura, H., Yuhashi, K. I., Yasuta, T., and Minamisawa, K. (2000). Effects of ethylene precursor and inhibitors for ethylene biosynthesis and perception on nodulation in Lotus japonicus and Macroptilium atropurpureum. Plant Cell Physiol. 41, 893-897. doi: 10.1093/pcp/pcd011

Okamoto, G., Jia, H., Kitamura, A., and Hirano, K. (2001). Effect of different fertilizer application levels on texture of 'hakuho' peach (Prunus persica Batsch). J. Jpn. Soc. Hortic. Sci. 70, 533-538. doi: 10.2503/jjshs.70.533

Okushima, Y., Inamoto, H., and Umeda, M. (2011). A high concentration of nitrate causes temporal inhibition of lateral root growth by suppressing cell proliferation. Plant Biotechnol. 28, 413-416. doi: 10.5511/plantbiotechnology.11.0722a

Oldroyd, G. E., Engstrom, E. M., and Long, S. R. (2001). Ethylene inhibits the Nod factor signal transduction pathway of Medicago truncatula. Plant Cell 13, 1835-1849. doi: 10.1105/tpc.13.8.1835

Oliveira, H. C., Freschi, L., and Sodek, L. (2013). Nitrogen metabolism and translocation in soybean plants subjected to root oxygen deficiency. Plant Physiol. Biochem. 66, 141-149. doi: 10.1016/j.plaphy.2013. 02.015

Oliveira, H. C., and Sodek, L. (2013). Effect of oxygen deficiency on nitrogen assimilation and amino acid metabolism of soybean root segments. Amino Acids 44, 743-755. doi: 10.1007/s00726-012-1399-3

Overmyer, K., Tuominen, H., Kettunen, R., Betz, C., Langebartels, C., Sandermann, H., et al. (2000). Ozone-sensitive Arabidopsis rcd1 mutant reveals opposite roles for ethylene and jasmonate signaling pathways in regulating superoxide-dependent cell death. Plant Cell 12, 1849-1862. doi: 10.1105/tpc.12.10.1849

Peng, M. S., Bi, Y. M., Zhu, T., and Rothstein, S. J. (2007). Genome-wide analysis of Arabidopsis responsive transcriptome to nitrogen limitation and its regulation by the ubiquitin ligase gene NLA. Plant Mol. Biol. 65, 775-797. doi: 10.1007/s11103-007-9241-0

Peng, M., Hudson, D., Schofield, A., Tsao, R., Yang, R., Gu, H., et al. (2008). Adaptation of Arabidopsis to nitrogen limitation involves induction of anthocyanin synthesis which is controlled by the NLA gene. J. Exp. Bot. 59, 2933-2944. doi: 10.1093/jxb/ern148

Penmetsa, R. V., and Cook, D. R. (1997). A legume ethylene-insensitive mutant hyperinfected by its rhizobial symbiont. Science 275, 527-530. doi: $10.1126 /$ science. 275.5299 .527

Peters, N. K., and Crist-Estes, D. K. (1989). Nodule formation is stimulated by the ethylene inhibitor aminoethoxyvinylglycine. Plant Physiol. 91, 690-693. doi: 10.1104/pp.91.2.690

Petrášek, J., and Friml, J. (2009). Auxin transport routes in plant development. Development 136, 2675-2688. doi: 10.1242/dev.030353

Ren, W., Li, D., Liu, H., Mi, R., Zhang, Y., and Dong, L. (2013). Lithium storage performance of carbon nanotubes with different nitrogen contents as anodes in lithium ions batteries. Electrochi. Acta 105, 75-82. doi: 10.1016/j.electacta.2013.04.145

Renault, H., El Amrani, A., Berger, A., Mouille, G., Soubigou-Taconnat, L., Bouchereau, A., et al. (2013). $\gamma$-Aminobutyric acid transaminase deficiency impairs central carbon metabolism and leads to cell wall defects during 
salt stress in Arabidopsis roots. Plant Cell Environ. 36, 1009-1018. doi: $10.1111 /$ pce. 12033

Roldan, M., Dinh, P., Leung, S., and McManus, M. T. (2013). Ethylene and the responses of plants to phosphate deficiency. AoB Plants 5, 1-10. doi: 10.1093/aobpla/plt013

Romera, F. J., and Alcantara, E. (1994). Iron-deficiency stress responses in cucumber (Cucumis sativus L.) roots (a possible role for ethylene?). Plant Physiol. 105, 1133-1138.

Rubin, G., Tohge, T., Matsuda, F., Saito, K., and Scheible, W. R. (2009). Members of the LBD family of transcription factors repress anthocyanin synthesis and affect additional nitrogen responses in Arabidopsis. Plant Cell 21, 3567-3584. doi: 10.1105/tpc.109.067041

Rubio, V., Bustos, R., Irigoyen, M. L., Cardona-López, X., Rojas-Triana, M., and Paz-Ares, J. (2009). Plant hormones and nutrient signaling. Plant Mol. Biol. 69, 361-373. doi: 10.1007/s11103-008-9380-y

Ruffel, S., Krouk, G., Ristova, D., Shasha, D., Birnbaum, K. D., and Coruzzi, G. M. (2011). Nitrogen economics of root foraging: transitive closure of the nitratecytokinin relay and distinct systemic signaling for $\mathrm{N}$ supply vs. demand. Proc. Natl. Acad. Sci. U.S.A. 108, 18524-18529. doi: 10.1073/pnas.1108684108

Růžička, K., Ljung, K., Vanneste, S., Podhorská, R., Beeckman, T., Friml, J., et al. (2007). Ethylene regulates root growth through effects on auxin biosynthesis and transport-dependent auxin distribution. Plant Cell 19, 2197-2212. doi: 10.1105/tpc.107.052126

Saiz-Fernández, I., De Diego, N., Sampedro, M. C., Mena-Petite, A., OrtizBarredo, A., and Lacuesta, M. (2015). High nitrate supply reduces growth in maize, from cell to whole plant. J. Plant Physiol. 173, 120-129. doi: 10.1016/j.jplph.2014.06.018

Sakakibara, H. (2006). Cytokinins: activity, biosynthesis, and translocation. Ann. Rev. Plant Biol. 57, 431-449. doi: 10.1146/annurev.arplant.57.032905.105231

Salama, A. M., and Wareing, P. F. (1979). Effects of mineral nutrition on endogenous cytokinins in plants of sunflower. J. Exp. Bot. 30, 971-981. doi: $10.1093 / \mathrm{jxb} / 30.5 .971$

Schmelz, E. A., Alborn, H. T., Engelberth, J., and Tumlinson, J. H. (2003). Nitrogen deficiency increases volicitin-induced volatile emission, jasmonic acid accumulation, and ethylene sensitivity in maize. Plant Physiol. 133, 295-306. doi: $10.1104 /$ pp.103.024174

Searles, P. S., and Bloom, A. J. (2003). Nitrate photo-assimilation in tomato leaves under short-term exposure to elevated carbon dioxide and low oxygen. Plant Cell Environ. 26, 1247-1255. doi: 10.1046/j.1365-3040.2003.0 1047.x

Sheen, J., Zhou, L., and Jang, J.-C. (1999). Sugars as signaling molecules. Curr. Opin. Plant Biol. 2, 410-418. doi: 10.1016/S1369-5266(99)00014-X

Shin, R., and Schachtman, D. P. (2004). Hydrogen peroxide mediates plant root cell response to nutrient deprivation. Proc. Natl. Acad. Sci. U.S.A. 101, 8827-8832. doi: 10.1073/pnas.0401707101

Signora, L., De Smet, I., Foyer, C. H., and Zhang, H. (2001). ABA plays a central role in mediating the regulatory effects of nitrate on root branching in Arabidopsis. Plant J. 28, 655-662. doi: 10.1046/j.1365-313x.2001.01185.x

Singh, S., Letham, D. S., Zhang, R., and Palni, L. M. S. (1992). Cytokinin biochemistry in relation to leaf senescence: IV. Effect of nitrogenous nutrient on cytokinin levels and senescence of tobacco leaves. Physiol. Plant. 84, 262-268. doi: 10.1111/j.1399-3054.1992.tb04663.x

Skottke, K. R., Yoon, G. M., Kieber, J. J., and De Long, A. (2011). Protein phosphatase $2 \mathrm{~A}$ controls ethylene biosynthesis by differentially regulating the turnover of ACC synthase isoforms. PLoS Genet. 7:e1001370. doi: 10.1371/journal.pgen. 1001370

Stenlid, G. (1982). Cytokinin as inhibitors of root growth. Physiol. Plant. 56, 500-506. doi: 10.1111/j.1399-3054.1982.tb04546.x

Stepanova, A. N., Hoyt, J. M., Hamilton, A. A., and Alonso, J. M. (2005). A link between ethylene and auxin uncovered by the characterization of two rootspecific ethylene-insensitive mutants in Arabidopsis. Plant Cell 17, 2230-2242. doi: $10.1105 /$ tpc. 105.033365

Stitt, M. (1999). Nitrate regulation of metabolism and growth. Curr. Opin. Plant Biol. 2, 178-186. doi: 10.1016/S1369-5266(99)80033-8

Sun, H., Li, J., Song, W., Tao, J., Huang, S., Chen, S., et al. (2015). Nitric oxide generated by nitrate reductase increases nitrogen uptake capacity by inducing lateral root formation and inorganic nitrogen uptake under partial nitrate nutrition in rice. J. Exp. Bot. 66, 2449-2459. doi: 10.1093/jxb/erv030
Sun, J., Cardoza, V., Mitchell, D. M., Bright, L., Oldroyd, G., and Harris, J. M. (2006). Crosstalk between jasmonic acid, ethylene and Nod factor signaling allows integration of diverse inputs for regulation of nodulation. Plant J. 46, 961-970. doi: 10.1111/j.1365-313X.2006.02751.x

Swarup, R., Perry, P., Hagenbeek, D., van der Straeten, D., Beemster, G. T., Sandberg, G., et al. (2007). Ethylene upregulates auxin biosynthesis in Arabidopsis seedlings to enhance inhibition of root elongation. Plant Cell 19, 2186-2196. doi: 10.1105/tpc.107.052100

Takahashi, H., Yamauchi, T., Rajhi, I., Nishizawa, N. K., and Nakazono, M. (2015). Transcript profiles in cortical cells of maize primary root during ethyleneinduced lysigenous aerenchyma formation under aerobic conditions. Ann. Bot. 115, 879-894. doi: 10.1093/aob/mcv018

Takehisa, H., Sato, Y., Antonio, B. A., and Nagamura, Y. (2013). Global transcriptome profile of rice root in response to essential macronutrient deficiency. Plant Signal. Behav. 8, e24409. doi: 10.4161/psb. 24409

Takei, K., Ueda, N., Aoki, K., Kuromori, T., Hirayama, T., Shinozaki, K., et al. (2004). AtIPT3 is a key determinant of nitrate-dependent cytokinin biosynthesis in Arabidopsis. Plant Cell Physiol. 45, 1053-1062. doi: $10.1093 / \mathrm{pcp} / \mathrm{pch} 119$

Tari, I., and Csiszár, J. (2003). Effects of NO2- or NO3- supply on polyamine accumulation and ethylene production of wheat roots at acidic and neutral pH: implications for root growth. Plant Growth Regul. 40, 121-128. doi: 10.1023/A:1024235211395

Tian, Q. Y., Sun, P., and Zhang, W. H. (2009). Ethylene is involved in nitratedependent root growth and branching in Arabidopsis thaliana. New Phytol. 184, 918-931. doi: 10.1111/j.1469-8137.2009.03004.X

Trevisan, S., Manoli, A., and Quaggiotti, S. (2014). NO signalling is a key component of the root growth response to nitrate in Zea mays L. Plant Signal. Behav. 9, e28290. doi: 10.4161/psb.28290

Trevisan, S., Manoli, A., Ravazzolo, L., Botton, A., Pivato, M., Masi, A., et al. (2015). Nitrate sensing by the maize root apex transition zone: a merged transcriptomic and proteomic survey. J. Exp. Bot. 66, 3699-3715. doi: 10.1093/jxb/ erv165

Trivellini, A., Cocetta, G., Vernieri, P., Mensuali-Sodi, A., and Ferrante, A. (2014). Effect of cytokinins on delaying petunia flower senescence: a transcriptome study approach. Plant Mol. Biol. 87, 169-180. doi: 10.1007/s11103-0140268-8

Trivellini, A., Ferrante, A., Vernieri, P., and Serra, G. (2011). Effects of abscisic acid on ethylene biosynthesis and perception in Hibiscus rosa-sinensis L. flower development. J. Exp. Bot. 62, 5437-5452. doi: 10.1093/jxb/err218

Trivellini, A., Jibran, R., Watson, L. M., O’Donoghue, E. M., Ferrante, A., Sullivan, K. L., et al. (2012). Carbon deprivation-driven transcriptomereprogramming in detached developmentally arresting Arabidopsis inflore-scences. Plant Physiol. 60, 1357-1372. doi: 10.1104/pp.112.203083

Tsuchisaka, A., and Theologis, A. (2004a). Unique and overlapping expression patterns among the Arabidopsis 1-amino-cyclopropane- 1-carboxylate synthase gene family members. Plant Physiol. 136, 2982-3000. doi: 10.1104/pp.104.049999

Tsuchisaka, A., and Theologis, A. (2004b). Heterodimeric interactions among the 1-amino-cyclopropane-1-carboxylate synthase polypeptides encoded by the Arabidopsis gene family. Proc. Natl. Acad. Sci. U.S.A. 101, 2275-2280. doi: 10.1073/pnas.0308515101

Tsuchisaka, A., Yu, G., Jin, H., Alonso, J. M., Ecker, J. R., Zhang, X., et al. (2009). A combinatorial interplay among the 1-aminocyclopropane-1-carboxylate isoforms regulates ethylene biosynthesis in Arabidopsis thaliana. Genetics 183, 979-1003. doi: 10.1534/genetics.109.107102

van Loon, L. C., Geraats, B. P. J., and Linthorst, H. J. M. (2006). Ethylene as a modulator of disease resistance in plants. Trends Plant Sci. 11, 184-191. doi: 10.1016/j.tplants.2006.02.005

Vidal, E. A., and Gutiérrez, R. A. (2008). A systems view of nitrogen nutrient and metabolite responses in Arabidopsis. Curr. Opin. Plant Biol. 11, 521-529. doi: 10.1016/j.pbi.2008.07.003

Vogel, M. O., Gomez-Perez, D., Probst, N., and Dietz, K. J. (2012). Combinatorial signal integration by APETALA2/Ethylene Response Factor (ERF)-transcription factors and the involvement of AP2-2 in starvation response. Int. J. Mol. Sci. 13, 5933-5951. doi: 10.3390/ijms1305 5933 
Wang, J., Wang, Y., Yang, J., Ma, C., Zhang, Y., Ge, T., et al. (2015). Arabidopsis ROOT HAIR DEFECTIVE3 is involved in nitrogen starvationinduced anthocyanin accumulation. J. Integr. Plant Biol. 57, 708-721. doi: 10.1111/jipb.12320

Wang, K. L., Li, H., and Ecker, J. R. (2002). Ethylene biosynthesis and signaling networks. Plant Cell 14, S131-S151.

Wang, K., Yoshida, H., Lurin, C., and Ecker, J. R. (2004). Regulation of ethylene gas biosynthesis by the Arabidopsis ETO1 protein. Nature 428, 945-950. doi: 10.1038 /nature 02516

Wang, L., Dong, J., Gao, Z., and Liu, D. (2012). The Arabidopsis gene hypersensitive to phosphate starvation 3 encodes ethylene overproduction 1. Plant Cell Physiol. 53, 1093-1110. doi: 10.1093/pcp/pcs072

Wargo, J. M., Merwin, I. A., and Watkins, C. B. (2004). Nitrogen fertilization, midsummer trunk girdling, and AVG treatments affect maturity and quality of 'Jonagold' apples. HortScience 39, 493-500.

Werner, T., Motyka, V., Laucou, V., De Smet, R., Van Onckelen, H., and Schmülling, T. (2003). Cytokinin-deficient transgenic Arabidopsis plants show multiple developmental alterations indicating opposite functions of cytokinins in the regulation of shoot and root meristem activity. Plant Cell 15, 2532-2550. doi: 10.1105/tpc.014928

Xu, G., Fan, X., and Miller, A. J. (2012). Plant nitrogen assimilation and use efficiency. Annu. Rev. Plant Biol. 63, 153-182. doi: 10.1146/annurev-arplant042811-105532

Xu, T., Qi, M., Shuangshuang, L. V., Zuo, X., Li, J., and Li, T. (2010). The effects of calcium on the expression of genes involved in ethylene biosynthesis and signal perception during tomato flower abscission. Afr. J. Biotechnol. 9, 3569-3576.

Yang, X. S., Wu, J., Ziegler, T. E., Yang, X., Zayed, A., Rajani, M. S., et al. (2011). Gene expression biomarkers provide sensitive indicators of in planta nitrogen status in maize. Plant Physiol. 157, 1841-1852. doi: 10.1104/pp.111.187898

Yendrek, C. R., Lee, Y. C., Morris, V., Liang, Y., Pislariu, C. I., Burkart, G., et al. (2010). A putative transporter is essential for integrating nutrient and hormone signaling with lateral root growth and nodule development in Medicago truncatula. Plant J. 62, 100-112. doi: 10.1111/j.1365-313X.2010.04134.x

Yoo, S.-D., Cho, Y.-H., Tena, G., Xiong, Y., and Sheen, J. (2008). Dual control of nuclear EIN3 by bifurcate MAPK cascades in C2H4 signalling. Nature 451, 789-795. doi: 10.1038/nature06543

Young, T. E., Meeley, R. B., and Gallie, D. R. (2004). ACC synthase expression regulates leaf performance and drought tolerance in maize. Plant J. 40, 813-825. doi: 10.1111/j.1365-313X.2004.02255.x

Zhang, G. B., Yi, H. Y., and Gong, J. M. (2014). The Arabidopsis ethylene/jasmonic acid-NRT signaling module coordinates nitrate reallocation and the trade-off between growth and environmental adaptation. Plant Cell 26, 3984-3998. doi: 10.1105/tpc.114.129296

Zhang, P. J., Broekgaarden, C., Zheng, S. J., Snoeren, T. A., Loon, J. J., Gols, R., et al. (2013). Jasmonate and ethylene signaling mediate whitefly-induced interference with indirect plant defense in Arabidopsis thaliana. New Phytol. 197, 1291-1299. doi: $10.1111 /$ nph.12106

Zhao, D. Y., Tian, Q. Y., Li, L. H., and Zhang, W. H. (2007). Nitric oxide is involved in nitrate-induced inhibition of root elongation in Zea mays. Ann. Bot. 100, 497-503. doi: 10.1093/aob/mcm 142

Zhao, W., Yang, X., Yu, H., Jiang, W., Sun, N., Liu, X., et al. (2015). RNA-Seqbased transcriptome profiling of early nitrogen deficiency response in cucumber seedlings provides new insight into the putative nitrogen regulatory network. Plant Cell Physiol. 56, 455-467. doi: 10.1093/pcp/pcu172

Zhao, Y., Wei, T., Yin, K. Q., Chen, Z., Gu, H., Qu, L. J., et al. (2012). Arabidopsis RAP2.2 plays an important role in plant resistance to Botrytis cinerea and ethylene responses. New Phytol. 195, 450-460. doi: 10.1111/j.14698137.2012.04160.x

Zheng, D., Han, X., An, Y., Guo, H., Xia, X., and Yin, W. (2013). The nitrate transporter NRT2.1 functions in the ethylene response to nitrate deficiency in Arabidopsis. Plant Cell Environ. 36, 1328-1337. doi: 10.1111/pce.12062

Zhou, C., Cai, Z., Guo, Y., and Gan, S. (2009). An Arabidopsis mitogen-activated protein kinase cascade, MKK9-MPK6, plays a role in leaf senescence. Plant Physiol. 150, 167-177. doi: 10.1104/pp.108.133439

Zhu, Q., Zhang, J. T., Gao, X. S., Tong, J. H., Xiao, L. T., Li, W. B., et al. (2010). The Arabidopsis AP2/ERF transcription factor RAP2.6 participates in ABA, salt and osmotic stress responses. Gene 457, 1-12. doi: 10.1016/j.gene.2010.02.011

Zuchi, S. S., Cesco, Z., Varanini, R., and Pinton, S. A. (2009). Sulphur deprivation limits Fe-deficiency responses in tomato plants. Planta 230, 85-94. doi: 10.1007/s00425-009-0919-1

Conflict of Interest Statement: The authors declare that the research was conducted in the absence of any commercial or financial relationships that could be construed as a potential conflict of interest.

Copyright (C) 2015 Khan, Trivellini, Fatma, Masood, Francini, Iqbal, Ferrante and Khan. This is an open-access article distributed under the terms of the Creative Commons Attribution License (CC BY). The use, distribution or reproduction in other forums is permitted, provided the original author(s) or licensor are credited and that the original publication in this journal is cited, in accordance with accepted academic practice. No use, distribution or reproduction is permitted which does not comply with these terms. 